\title{
Fresh state stability of vertical layers of concrete
}

\section{Citation:}

Torelli G, Lees JM (2019) Fresh state stability of vertical layers of concrete. Cement and Concrete Research 120:227243. doi: 10.1016/J.CEMCONRES.2019.03.006

\section{Additional Information:}

- Available online as of April $3^{\text {rd }} 2019$ : https://www.sciencedirect.com/science/article/pii/S0008884618312006

- $\quad$ DOI: https://doi.org/10.1016/j.cemconres.2019.03.006

- Additional data related to this publication is available at the University of Cambridge's institutional data repository: https://doi.org/10.17863/CAM.37979.

\section{Version:}

Accepted for publication 
Fresh state stability of vertical layers of concrete

Giacomo Torelli $^{*}$, Janet M. Lees ${ }^{1}$

${ }^{1}$ Department of Engineering, University of Cambridge, Cambridge, CB2 1PZ, UK

*Corresponding author, E-mail: gt384@cam.ac.uk, Tel: +44 7478297450 


\begin{abstract}
The production of cement is currently associated with around 5\% of global carbon emissions. The manufacture of functionally graded structural elements, where the material composition is varied over the volume, allows the use of cement to be optimized and minimized. Horizontal gradation of material properties can be achieved by casting vertical layers having homogeneous composition. However, a key problem in this application is the control of the fresh state deformations of the layers. This study investigates for the first time the fundamental problem of the fresh state stability of concrete prisms that consist of two vertical layers of different mixes. Original experiments are designed to invoke stable and unstable behaviour. Two novel limit-state models are formulated to assess the stability of the system as a function of material properties and geometry. The results show that a relationship between system stability, geometry and material parameters exists, and that it is captured by the presented models.
\end{abstract}

\title{
Keywords
}

Concrete; Fresh concrete; Rheology; Multilayer casting; Formwork

\section{Introduction}

Cementitious materials are the most widely used materials in construction. In the past decade, the global use of cement has increased from 2.22 to $4.10 \mathrm{Gt} /$ year [1]. In 2014, the industrial production of cement was estimated to account for $5.2 \%$ of global $\mathrm{CO}_{2}$ emissions [2]. Total annual greenhouse gas emissions have increased steadily since 1970, and reached a record high of $53.5 \mathrm{GtCO}_{2} \mathrm{e}$ in 2017 [3]. In response to this trend, 195 countries adopted a universal, legally-binding global climate agreement dealing with greenhouse gas emissions at the Paris climate conference COP21 in 2015 [4]. The Paris climate agreement sets out a global action plan to avoid dangerous climate change by limiting global warming [4]. To achieve a target maximum temperature increase of $1.5^{\circ} \mathrm{C}$ above pre-industrial levels, global greenhouse emissions in 2030 need to be approximately 55\% lower than in 2017 [3]. The development of technologies aimed at using cement efficiently is thus essential to meet this universal target. 
Traditionally, structural elements are designed and manufactured as homogeneous continua having uniform properties throughout their geometry. For a given element, a suitable material is chosen to meet various requirements, such as a strength, durability and deformability performance. With this approach, the properties of the material are often fully exploited only in limited regions of the element. For example, when the material is selected to meet a desired strength performance, its mechanical strength capacity is only reached in the areas where critical stress states are expected to develop. For a majority of load cases, this results in an overuse of high performance material and thus in a generally inefficient design.

The need to use materials efficiently leads to the concept of Functionally Graded Materials (FGMs). A FGM is a material whose properties change over the volume along one or multiple dimensions in order to effectively meet specific performance requirements [5]. That is, in a functionally graded element the material properties are engineered to meet the actual needs. The potential of FGMs was significantly developed in the 1980s in Japan, where functional grading was used to reduce the thermal stresses in conventional laminate composite materials for reusable rocket engines [6]. Since then, there has been an increasing interest in FGMs with successful applications in the aerospace, bioengineering and energy industries [7-9]. In aerospace, for example, FGMs capable of withstanding high thermal gradients are employed extensively in rocket engine components, leading edges of missiles and space shuttles. In bioengineering, man-made FGMs are widely used to replace damaged human body tissues presenting a natural gradation in mechanical properties. Common applications of FGMs in the energy sector are, for instance, thermal barrier coatings and pressure vessels. Comprehensive reviews on FGMs, processing techniques and applications are presented in [9-14].

The concept of FGMs has been applied to concrete elements, such as beams, slabs, and pavements. The material properties are commonly graded in the vertical direction to minimize self-weight and cement content and to optimize the overall mechanical and durability performance [15-19]. The change in properties in the vertical direction is obtained by sequentially casting horizontal layers of different concrete mixes. In order to achieve a good bond at the interface, wet-on-wet casting is typically used, i.e. new layers are cast prior to setting of the existing ones. While research has been carried out on horizontal layers, little attention has been paid to the possibility of grading material in the horizontal direction. Yet horizontal gradation represents a clear opportunity to minimize the use of cement and optimize properties such as the durability and fire resistance of, for example, beams, columns and walls. A first attempt to cast vertical layers is reported in [20]. In this study, vertical panels were used to demarcate the different mixes during casting and were then removed before compaction in order to obtain a good bond between the layers. 
However, a major problem with this kind of application is the control of the fresh state deformations of the vertical layers following the removal of a vertical dividing panel (as shown schematically in Figure 1). Indeed, if the mixes are fluid enough, global instability phenomena can occur where heavier mixes tend to flow underneath lighter mixes. If the flow due to global instability causes significant deformations, the layered geometry previously defined by the dividing panels is altered. As a consequence, the spatial variation of material properties in the hardened state does not reflect the original design, and the performance of the layered element might not be as expected. Thus, there is an urgent need to understand the problem of stability of vertical layers of fresh concrete in order to confidently design light, durable and safe multifunctional concrete structures.

Cementitious materials are yield stress fluids: they exhibit a viscoelastic solid behaviour at low shear stresses and start to flow at shear stresses higher than their yield stress [21-23]. When layered elements composed of columns of different materials are cast with the aid of a removable panel with a finite thickness, the extraction of the panel creates a void. This typically induces higher shear stresses than the yield stresses of the materials. As a result, a shear rate is generated and the materials flow in to fill the void. Once the materials come into contact, the shear stresses in the two mixes reduce due to mutual confinement in the horizontal direction. If the materials have the same self-weight, the shear stresses drop below the yield stresses and the flow stops. On the other hand, in cases where there are sufficiently high differences in density, shear stresses exceeding the yield stress of the materials may still exist. This results in the global instability of the system: additional flow occurs until a stress state is reached that does not exceed the yield stresses of the materials. Hence, density and yield stress of the selected materials play a key role in the stability of the system. 


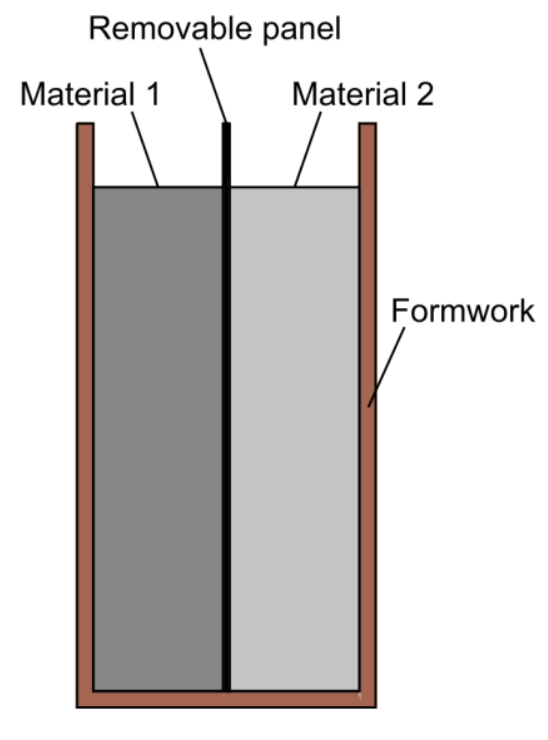

a)

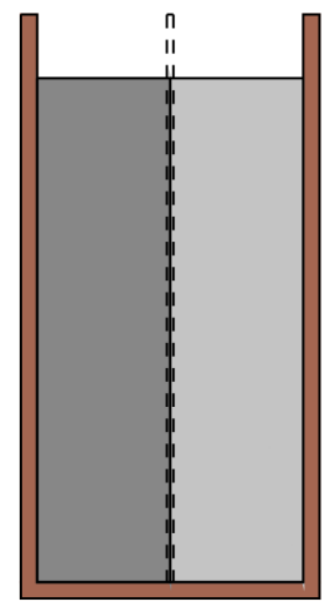

b.1)

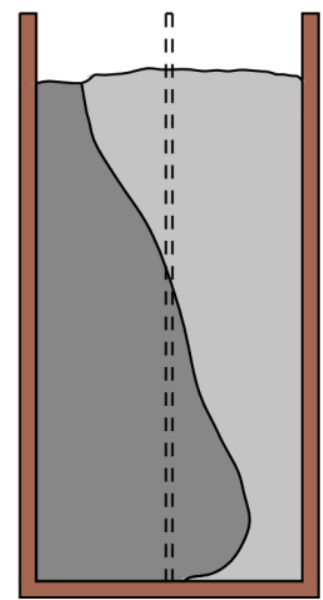

b.2)

Figure 1 (a) Casting of vertical layers with the aid of a removable panel; deformation of the layers following panel removal: (b.1) stable system and (b.2) unstable system.

This work makes a major contribution to research on functionally graded concrete by identifying the relationship between density, yield stress, geometry and mechanical stability of two vertical layers of fresh concrete in contact with each other. A set of experiments on two vertical layers with tailored cementitious mixes are designed to establish the relationship between material parameters and fresh state stability for a given geometry. Cementitious mixes with various yield stresses and densities are employed to invoke stable and unstable behaviour. An original limit state analysis method based on the lower and upper bound theorems of plasticity theory is then developed that allows the stability of the system to be predicted as a function of material parameters and geometry. The formulated limit-state approach is validated and discussed in light of experimental results.

\section{Experimental program}

A set of experiments were performed to investigate the effects of material properties on the stability of two columns of different materials. Specifically, vertical layers with tailored cementitious mixes having various yield stresses and densities were designed. The density of the materials was varied by adding foam to the mixes, while the yield stress was varied by altering the water content and using a polycarboxylate ether (PCE) superplasticizer. 


\subsection{Materials and protocols}

Twelve tests were performed, denoted as T1 to T12. In each test, two different cementitious materials, denoted as MX.1 and MX.2 were mixed, where X is the identifier of the test. The two mixes MX.1 and MX.2 were used to cast two identical layered prisms, denoted as $A$ and $B$, composed of two layers of different materials. This resulted in the casting of 24 layered prisms across 24 mix compositions.

\subsubsection{Materials}

The mix compositions were designed with a view to explore a wide range of densities and yield stress values. The mixes adopted in this study were mortars. A major advantage of using mortar, rather than concrete with coarse aggregate, is the possibility to effectively tailor a wide range of mix densities through the addition of foam without affecting the inner stability of the material. Indeed, special care must be taken when varying the density of a normal concrete mix with coarse aggregate by a mere addition of foam. This is because an increase in foam content reduces the density of the mortar phase, thereby potentially leading to segregation of coarse aggregate from mortar. Preliminary tests were performed, where uniform mortar prisms were cast to verify the inner stability of the mix compositions adopted in this study.

Table 1 shows the composition for the 24 mixes used, denoted as M1.1 to M12.2. A standard Portlandlimestone cement CEM II/A-LL strength class 32.5R complying with European Standard EN 197-1 [24] was used. The maximum particle diameter of the sand was $4 \mathrm{~mm}$. The desired workability (yield stress) was achieved by varying the water content and using a PCE superplasticizer. In order to visually distinguish between the two materials employed in each test, a red mortar dye based on powdered oxide pigments was added to one of the mixes. The foam was produced in the laboratory prior to each test using a surfactant-based foaming agent. First, the foaming agent was diluted in water to obtain a 3\% strength pre-foaming solution. Then, the foam was obtained by whisking the solution for two minutes using a mixer attachment fitted to a power drill. The densities of the single mix constituents are reported in Table 2. 
Table 1 Mix compositions.

*Superplasticizer content expressed in terms of $\%$ of cement mass

\begin{tabular}{|c|c|c|c|c|c|c|c|c|c|}
\hline \multirow{2}{*}{ Constituent } & \multirow{2}{*}{ Unit } & \multicolumn{2}{|c|}{ T1 } & \multicolumn{2}{|c|}{$\mathbf{T 2}$} & \multicolumn{2}{|c|}{ T3 } & \multicolumn{2}{|c|}{ T4 } \\
\hline & & M1.1 & M1.2 & M2.1 & M2.2 & M3.1 & M3.2 & M4.1 & M4.2 \\
\hline Cement & {$\left[\mathrm{kg} \mathrm{m}^{-3}\right]$} & 600 & 460 & 600 & 460 & 600 & 460 & 600 & 484 \\
\hline Water & {$\left[\mathrm{kg} \mathrm{m}^{-3}\right]$} & 300 & 230 & 300 & 230 & 300 & 230 & 300 & 243 \\
\hline Sand $0 / 4 \mathrm{~mm}$ & {$\left[\mathrm{~kg} \mathrm{~m}^{-3}\right]$} & 1314 & 1108 & 1309 & 1108 & 1309 & 1100 & 1309 & 1047 \\
\hline Superplasticizer* & {$[\%]$} & 0.35 & 0.00 & 0.70 & 0.00 & 0.70 & 0.70 & 0.70 & 0.70 \\
\hline Foam & {$\left[1 \mathrm{~m}^{-3}\right]$} & - & 200 & - & 200 & - & 200 & - & 200 \\
\hline Concrete dye & {$\left[\mathrm{kg} \mathrm{m}^{-3}\right]$} & 15 & - & 15 & - & 15 & - & 15 & - \\
\hline \multirow{2}{*}{ Constituent } & \multirow{2}{*}{ Unit } & \multicolumn{2}{|c|}{ T5 } & \multicolumn{2}{|c|}{ T6 } & \multicolumn{2}{|c|}{$\mathbf{T 7}$} & \multicolumn{2}{|c|}{ T8 } \\
\hline & & M5.1 & M5.2 & M6.1 & M6.2 & M7.1 & M7.2 & M8.1 & M8.2 \\
\hline Cement & {$\left[\mathrm{kg} \mathrm{m}^{-3}\right]$} & 600 & 519 & 600 & 519 & 600 & 519 & 600 & 519 \\
\hline Water & {$\left[\mathrm{kg} \mathrm{m}^{-3}\right]$} & 300 & 259 & 300 & 259 & 300 & 259 & 300 & 259 \\
\hline Sand (0/4 mm) & {$\left[\mathrm{kg} \mathrm{m}^{-3}\right]$} & 1320 & 1245 & 1314 & 1240 & 1309 & 1236 & 1304 & 1236 \\
\hline Superplasticizer* & [\%] & 0.00 & 0.00 & 0.35 & 0.35 & 0.70 & 0.70 & 1.05 & 0.70 \\
\hline Foam & {$\left[1 \mathrm{~m}^{-3}\right]$} & - & 100 & - & 100 & - & 100 & - & 100 \\
\hline Concrete dye & {$\left[\mathrm{kg} \mathrm{m}^{-3}\right]$} & 15 & - & 15 & - & 15 & - & 15 & - \\
\hline \multirow{2}{*}{ Constituent } & \multirow{2}{*}{ Unit } & \multicolumn{2}{|c|}{ T09 } & \multicolumn{2}{|c|}{ T10 } & \multicolumn{2}{|c|}{ T11 } & \multicolumn{2}{|c|}{ T12 } \\
\hline & & M9.1 & M9.2 & M10.1 & M10.2 & M11.1 & M11.2 & M12.1 & M12.2 \\
\hline Cement & {$\left[\mathrm{kg} \mathrm{m}^{-3}\right]$} & 600 & 575 & 600 & 519 & 600 & 575 & 600 & 600 \\
\hline Water & {$\left[\mathrm{kg} \mathrm{m}^{-3}\right]$} & 300 & 288 & 300 & 259 & 300 & 288 & 300 & 300 \\
\hline Sand (0/4 mm) & {$\left[\mathrm{kg} \mathrm{m}^{-3}\right]$} & 1304 & 1114 & 1309 & 1366 & 1309 & 1254 & 1304 & 1322 \\
\hline Superplasticizer* & {$[\%]$} & 1.05 & 0.70 & 0.70 & 0.70 & 0.70 & 0.00 & 1.05 & 0.70 \\
\hline Foam & {$\left[1 \mathrm{~m}^{-3}\right]$} & - & 100 & - & 50 & - & 50 & - & - \\
\hline Concrete dye & {$\left[\mathrm{kg} \mathrm{m}^{-3}\right]$} & 15 & - & 15 & - & 15 & - & 15 & - \\
\hline
\end{tabular}

Table 2 Densities of the mix constituents

\begin{tabular}{lc}
\hline Constituent & $\begin{array}{c}\text { Density } \\
{\left[\mathbf{k g ~ m}^{-3}\right]}\end{array}$ \\
\hline Cement & 3200 \\
Water & 1000 \\
Sand $(0 / 4 \mathrm{~mm})$ & 2600 \\
Superplasticizer & 1100 \\
Foam & 50 \\
Concrete dye & 3000 \\
\hline
\end{tabular}




\subsubsection{Mixing protocols}

Each of the 12 tests involved mixing two different mortars, measuring their weight and rheological properties, and casting vertically layered prisms. The two mortars were mixed simultaneously. The mixes without foam were mixed in a vertical-axis rotational mixer. The dry ingredients, including the dye, were mixed for 2 minutes in order to obtain a homogenous blend. The water was then added gradually while the mixer was running and the wet ingredients were mixed for an additional 2 minutes. By contrast, the foamed concretes were mixed in an inclined drum mixer. The benefit of using a drum mixer was that its relatively gentle folding action allowed the foam to blend uniformly with the mortar without collapsing. As with the mixes without foam, the ingredients were first mixed dry for 2 minutes and wet for an additional 2 minutes. The foam was then gradually added and the mixer was left running for another 2 minutes in order to achieve a homogenous foamed mix.

\subsubsection{Rheological measurements}

In order to minimize the effects of thixotropy, measurements of the fresh state properties and stability tests were performed and completed within 10 minutes after mixing. The yield stress of the wet mixes was measured through an LCPC-box channel flow test $[25,26]$. This test measures the ability of the mix to flow through a wooden box having a length of $120 \mathrm{~cm}$, a width of $20 \mathrm{~cm}$ and a height of $15 \mathrm{~cm}$ (see Figure 2). Six litres of material are poured at one extreme of the box in about 30 seconds, thereby generating a relatively slow flow that stops only when the stresses within the material are equal to or less than the yield stress. The yield stress $\tau_{0}$ is calculated as a function of wet density $\rho$ and spread length $L$ in the box, defined as the average of the maximum spread length and lateral wall spread length. The relationship between wet density, spread lengths, and yield stress is obtained analytically in [27]. The reliability of the method was demonstrated by Roussel [25] and Nguyen et al. [27] by cross validating the obtained measures against the results of rotational rheometer tests. The LCPC-box test is preferred to the classic slump flow test in the case of highly flowable mixes, such as the mortars studied here. This is because when the slump flow test is performed with highly flowable mixes, the thickness of the sample at flow stoppage is often of the same order as the size of the largest particles [25]. In addition, the LCPC-box allows a relatively slow flow rate to be imposed, thus justifying the existence of a relationship between shape at stoppage, density and yield stress of the material [25]. The yield stress of the two materials employed in each test was measured at the same time and immediately before casting the layered prisms in order to obtain a reliable assessment of the instantaneous values. The wet density of each mix was measured at the same time by weighing eight litres of material. 


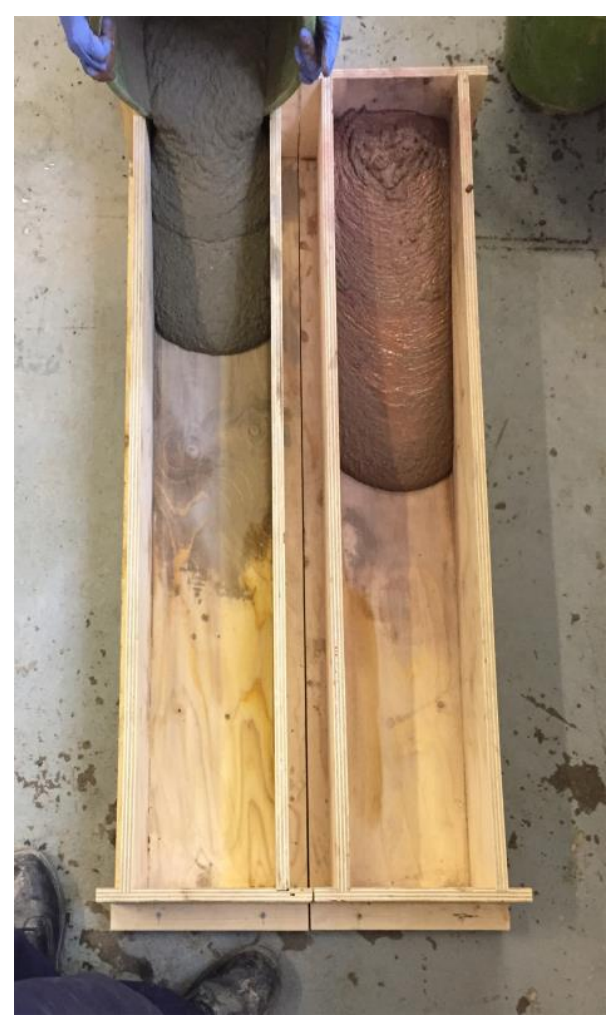

Figure 2 LCPC-box test

\subsubsection{Main experiments}

As discussed for each test, two identical repeat specimens were cast. Rectangular wooden moulds equipped with a removable vertical panel was designed to cast the specimens (see Figure 3). The internal dimensions of the moulds were $16.4 \times 30 \times 35 \mathrm{~cm}^{3}$. To host the removable panel, two vertical grooves were cut into the internal surfaces of the short sides of each mould. The vertical panel was made of acrylic glass and was $4 \mathrm{~mm}$ thick, therefore dividing the internal volume of the mould into two distinct regions having a thickness of $8 \mathrm{~cm}$. 


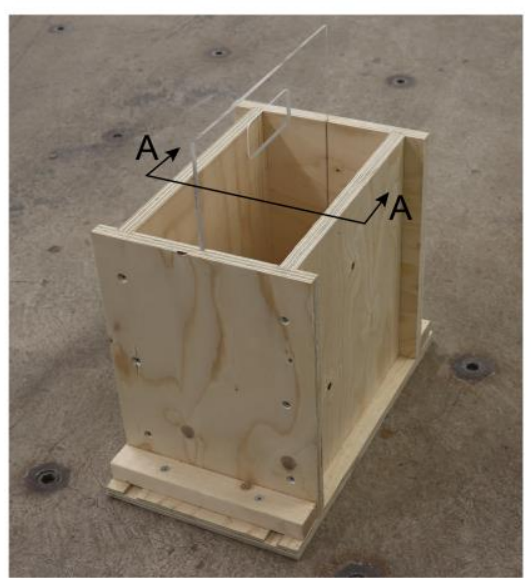

a)

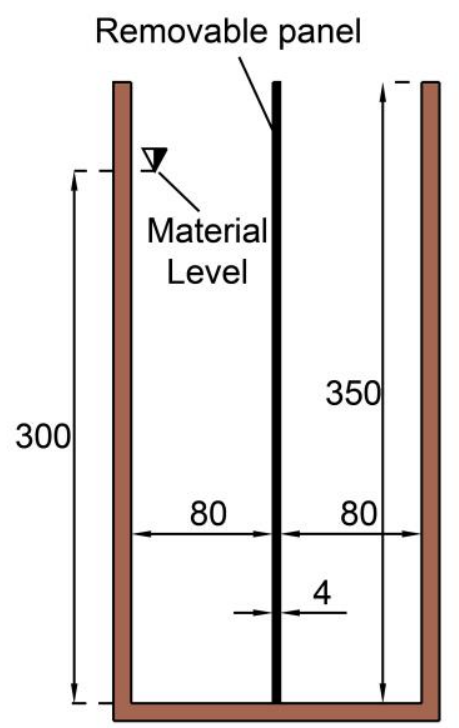

b)

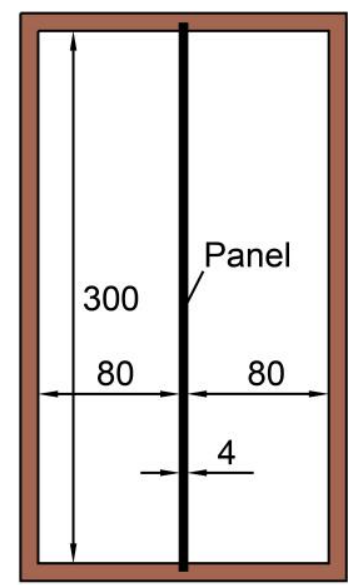

c)

Figure 3 (a) Mould equipped with removable panel, (b) vertical section A-A and (c) plan view.

First, the removable panel was oiled to minimize the friction effects on sliding. Then, two different mixes were cast in the two regions of the mould. In order to avoid deflection of the panel, the two mixes were cast to similar heights during casting. The two regions of the mould were filled up to a height of $30 \mathrm{~cm}$. The dividing panel was then removed immediately after casting and at this point the two mixes came into contact. To avoid inducing inertial effects, the panel was extracted in approximately 10 seconds, corresponding to a relatively low speed of $30 \mathrm{~mm} \mathrm{~s}^{-1}$. The two columns of material deformed to fill the gap created by the panel extraction.

The specimens were cured for at least 3 days, demoulded, and cut in half along the vertical plan parallel to their short sides using a table saw with a blade diameter of $400 \mathrm{~mm}$. This allowed the middle cross section of 
the specimens to be inspected (see Figure 4a). First, the cross sections were photographed with a highresolution camera (Figure 4b). The perspective distortions were minimized upstream by ensuring the focal plane was parallel to the cuts. Then, the residual distortions were corrected in a raster graphic editor by marking four reference points on the cross section of each specimen. The corrected photos were finally imported into a CAD software in order to trace the profile of the boundary between the two mixes and to measure the transversal displacement $d$, defined here as the maximum horizontal displacement of the boundary (see Figure $4 c)$.

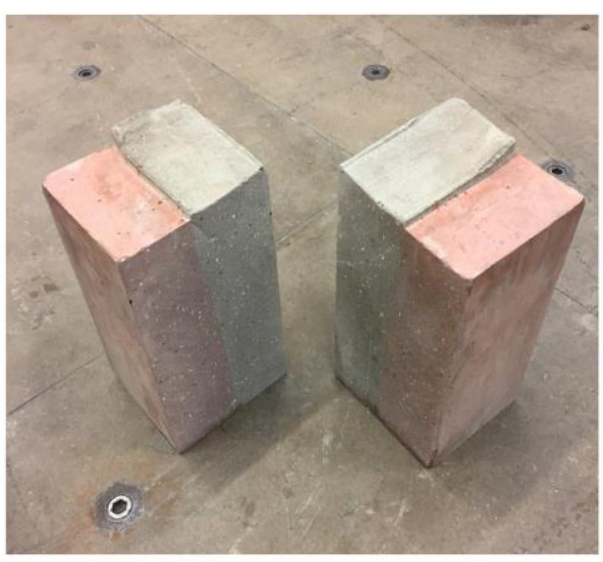

a)
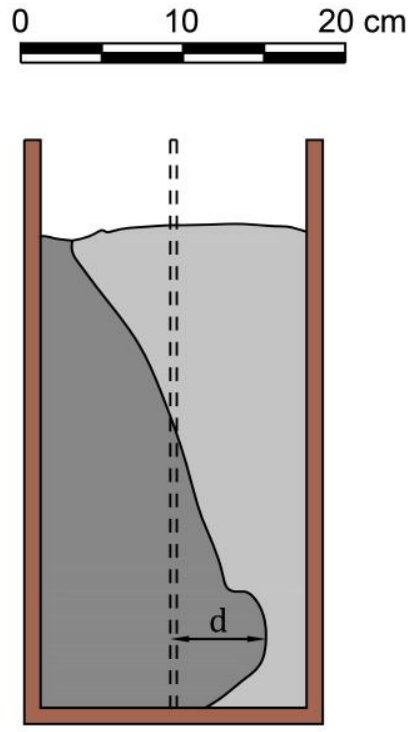

c)

Figure 4 Analysis of the middle section of a specimen: (a) specimen cut in half, (b) photo of a middle section, (c) CAD representation of the middle section.

\subsection{Results}

\subsubsection{Rheological measurements}

Table 3 summarizes the material properties measured for all the mixes and the driving parameters derived for each test, i.e. difference in density $\Delta \rho$ between the materials, the sum of the yield stresses $\tau_{s}$, and the stability coefficient $m$, defined here as:

$$
m=\frac{\tau_{s}}{\Delta \rho}
$$

Such a coefficient was defined as an indicator of the stability capacity of the system. Indeed, the difference in density $\Delta \rho$ is proportional to the forces driving instability while the sum of yield stresses $\tau_{s}$ is an indicator of the ability of the system to withstand shear stresses in the stable regime. 
The adopted mix compositions allowed a wide range of densities and yield stresses to be obtained. It is worth noting that Tests 1 to 4 (T1-T4) are characterised by $\Delta \rho$ in the range $350-368 \mathrm{~kg} \mathrm{~m}^{-3}$ and decreasing $\tau_{s}$. This results in a decreasing stability index $m$. Similar variations of $\tau_{s}$ and $m$ can be observed for Tests 5 to 9 (T5T9), where $\Delta \rho=194-228 \mathrm{~kg} \mathrm{~m}^{-3}$, and Tests 10 to 12 (T10-T12), where $\Delta \rho=75-142 \mathrm{~kg} \mathrm{~m}^{-3}$.

\subsubsection{Main experiments}

In all the tests, the heavier material tends to flow underneath the lighter material. As an example, Figure 5 shows the flow profiles obtained at the middle section of each specimen $A$.

Visual observation of the hardened prisms allowed for the verification that the short lateral faces of all specimens did not deform (see Figure 6). That is, the fresh materials stuck to the wooden walls. However, the inspection of the boundary between the two materials at the top surface of the prisms showed that the short lateral faces affected only a limited region of the specimens having a maximum thickness of $9 \mathrm{~cm}$. 
Table 3 Experimental measurements for the mixes under investigation (wet density $\rho$, spread length $L$ and yield stress $\tau_{0}$ ), driving parameters for each test, and transversal displacements (displacement $d_{A}$ measured for the repeat specimens $A$, displacements $d_{B}$ measured for the repeat specimens $B$, and average displacements $d$ ).

\begin{tabular}{|c|c|c|c|c|c|c|c|c|c|}
\hline \multirow{2}{*}{ Measure } & \multirow{2}{*}{ Unit } & \multicolumn{2}{|c|}{ Test 1} & \multicolumn{2}{|c|}{ Test 2} & \multicolumn{2}{|c|}{ Test 3} & \multicolumn{2}{|c|}{ Test 4} \\
\hline & & M1.1 & M1.2 & M2.1 & M2.2 & M3.1 & M3.2 & M4.1 & M4.2 \\
\hline$\rho$ & {$\left[\mathrm{kg} \mathrm{m}^{-3}\right]$} & 2228 & 1898 & 2235 & 1867 & 2100 & 1750 & 2180 & 1805 \\
\hline$L$ & {$[\mathrm{~mm}]$} & 600 & 480 & 740 & 490 & 650 & 650 & 830 & 720 \\
\hline$\tau_{0}$ & {$[\mathrm{~Pa}]$} & 76 & 116 & 42 & 109 & 57 & 47 & 30 & 37 \\
\hline$\Delta \rho=\rho_{1}-\rho_{2}$ & {$\left[\mathrm{~kg} \mathrm{~m}^{-3}\right]$} & \multicolumn{2}{|c|}{330} & \multicolumn{2}{|c|}{368} & \multicolumn{2}{|c|}{350} & \multicolumn{2}{|c|}{375} \\
\hline$\tau_{s}=\tau_{1}+\tau_{2}$ & {$[\mathrm{~Pa}]$} & \multicolumn{2}{|c|}{192} & \multicolumn{2}{|c|}{151} & \multicolumn{2}{|c|}{104} & \multicolumn{2}{|c|}{67} \\
\hline$m=\tau_{s} / \Delta \rho$ & {$\left[\mathrm{Pa} \mathrm{m}^{3} \mathrm{~kg}^{-1}\right]$} & \multicolumn{2}{|c|}{0.58} & \multicolumn{2}{|c|}{0.41} & \multicolumn{2}{|c|}{0.30} & \multicolumn{2}{|c|}{0.18} \\
\hline$\alpha=\tau_{\min } / \tau_{\max }$ & {$[-]$} & \multicolumn{2}{|c|}{0.65} & \multicolumn{2}{|c|}{0.39} & \multicolumn{2}{|c|}{0.83} & \multicolumn{2}{|c|}{0.82} \\
\hline$d_{A}$ & {$[\mathrm{~mm}]$} & \multicolumn{2}{|c|}{7.9} & \multicolumn{2}{|c|}{11.4} & \multicolumn{2}{|c|}{37.8} & \multicolumn{2}{|c|}{59.0} \\
\hline$d_{B}$ & {$[\mathrm{~mm}]$} & & & & & & & & \\
\hline$d$ & {$[\mathrm{~mm}]$} & & & & & & & & .0 \\
\hline Measure & Unit & & t 5 & Te & & & 7 & & t 8 \\
\hline vieasure & Unit & M5.1 & M5.2 & M6.1 & M6.2 & M7.1 & M7.2 & M8.1 & M8.2 \\
\hline$\rho$ & {$\left[\mathrm{kg} \mathrm{m}^{-3}\right]$} & 2140 & 1946 & 2165 & 1960 & 2165 & 1940 & 2150 & 1922 \\
\hline$L$ & {$[\mathrm{~mm}]$} & 605 & 400 & 660 & 490 & 740 & 570 & 920 & 575 \\
\hline$\tau_{0}$ & {$[\mathrm{~Pa}]$} & 71 & 176 & 56 & 114 & 41 & 76 & 23 & 74 \\
\hline$\Delta \rho=\rho_{1}-\rho_{2}$ & {$\left[\mathrm{~kg} \mathrm{~m}^{-3}\right]$} & & & & & & & & \\
\hline$\tau_{s}=\tau_{1}+\tau_{2}$ & {$[\mathrm{~Pa}]$} & & & & & & & & \\
\hline$m=\tau_{s} / \Delta \rho$ & {$\left[\mathrm{Pa} \mathrm{m}^{3} \mathrm{~kg}^{-1}\right]$} & & & & & & & & \\
\hline$\alpha=\tau_{\min } / \tau_{\max }$ & {$[-]$} & & & & & & & & \\
\hline$d_{A}$ & {$[\mathrm{~mm}]$} & & & & & & & & .8 \\
\hline$d_{B}$ & {$[\mathrm{~mm}]$} & & & & & & & & \\
\hline$d$ & {$[\mathrm{~mm}]$} & & & & & & & & \\
\hline Mea & $\mathbf{I n}$ & & t 9 & Tes & 10 & Te & 11 & Tes & 12 \\
\hline vieasure & Unit & M9.1 & M9.2 & M10.1 & M10.2 & M11.1 & M11.2 & M12.1 & M12.2 \\
\hline$\rho$ & {$\left[\mathrm{kg} \mathrm{m}^{-3}\right]$} & 2130 & 1922 & 2137 & 1995 & 2145 & 2020 & 2182 & 2107 \\
\hline$L$ & {$[\mathrm{~mm}]$} & 915 & 730 & 690 & 505 & 725 & 520 & 1190 & 680 \\
\hline$\tau_{0}$ & {$[\mathrm{~Pa}]$} & 23 & 37 & 49 & 108 & 43 & 101 & 11 & 50 \\
\hline$\Delta \rho=\rho_{1}-\rho_{2}$ & {$\left[\mathrm{~kg} \mathrm{~m}^{-3}\right]$} & & & & & & & & \\
\hline$\tau_{s}=\tau_{1}+\tau_{2}$ & {$[\mathrm{~Pa}]$} & & & & & & 14 & & \\
\hline$m=\tau_{s} / \Delta \rho$ & {$\left[\mathrm{Pa} \mathrm{m}^{3} \mathrm{~kg}^{-1}\right]$} & & & & & & & & \\
\hline$\alpha=\tau_{\min } / \tau_{\max }$ & {$[-]$} & & & & & & & & \\
\hline$d_{A}$ & {$[\mathrm{~mm}]$} & & & & & & 5 & & \\
\hline$d_{B}$ & {$[\mathrm{~mm}]$} & & & & & & 1 & & \\
\hline$d$ & {$[\mathrm{~mm}]$} & & & & & & 3 & & 6 \\
\hline
\end{tabular}



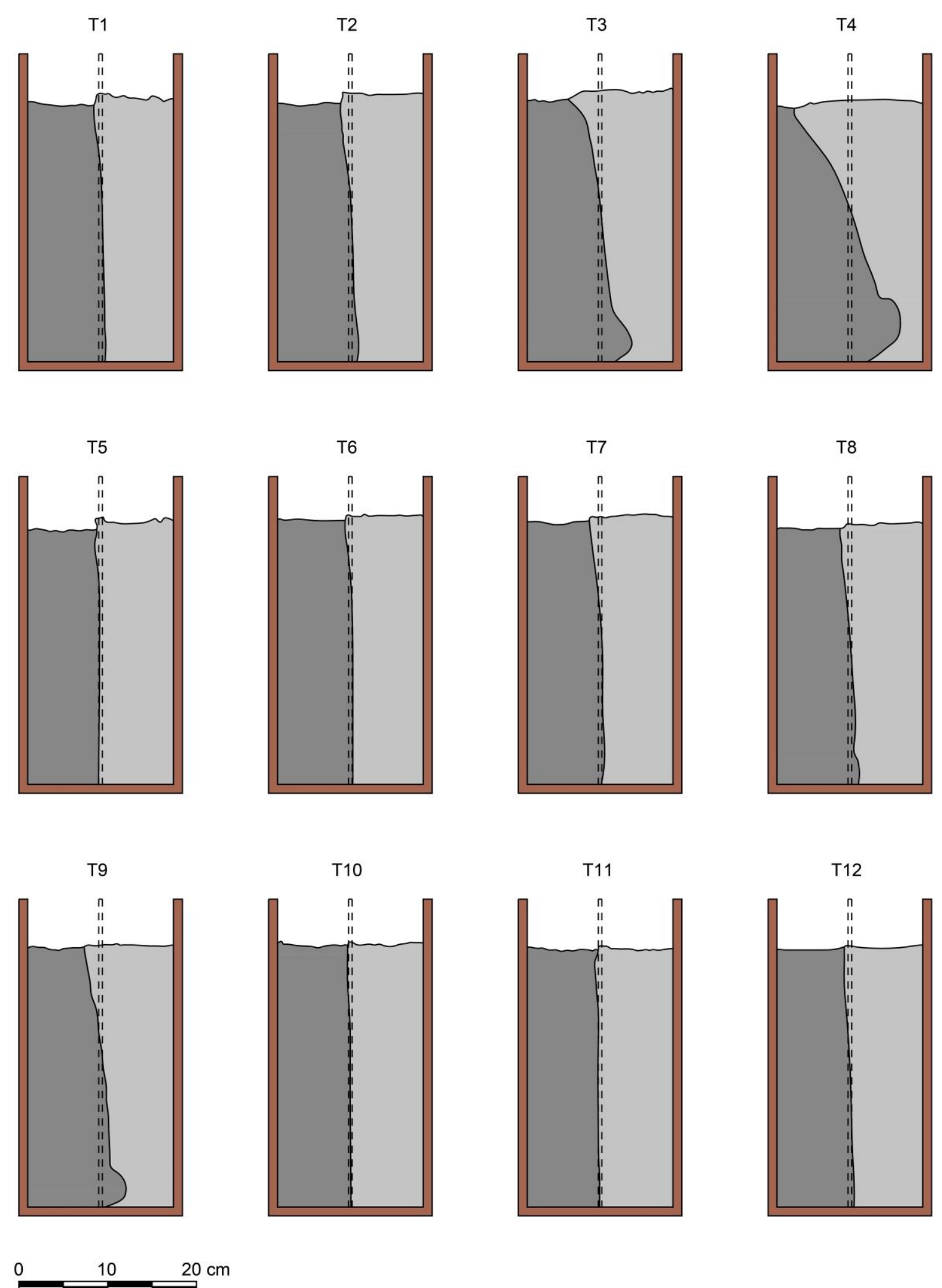

$20 \mathrm{~cm}$

Figure 5 Middle sections of specimen A at flow stoppage 


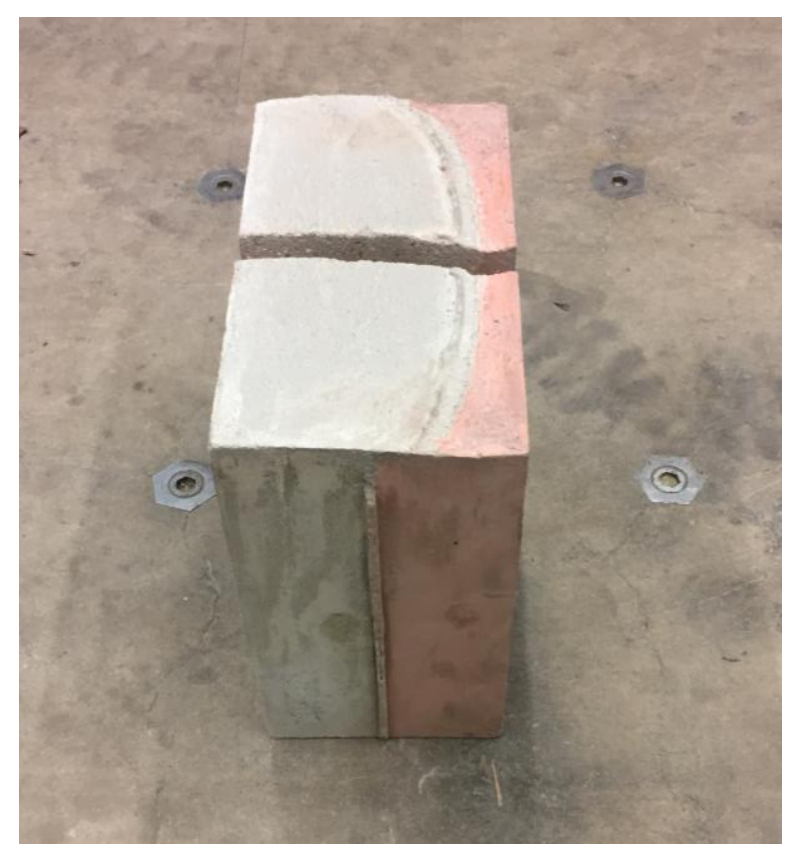

Figure $63 \mathrm{D}$ view of specimen T4A

Table 3 summarizes the horizontal displacements $d_{A}$ and $d_{B}$ measured for the specimens $A$ and $B$ respectively, together with their average value $d$. Figure 7 shows the variation of the average displacement $d$ in the $\Delta \rho-\tau_{s}$ plane. Following the same trend as indicated by the stability index $m$, the displacement $d$ grows with increasing differences in densities $\Delta \rho$ and decreasing sums of yield stresses $\tau_{s}$. Specifically, $d$ grows from $8.8 \mathrm{~mm}$ to 59 $\mathrm{mm}$ for tests $\mathrm{T} 1$ to $\mathrm{T} 4$, from $2 \mathrm{~mm}$ to $30.9 \mathrm{~mm}$ for tests $\mathrm{T} 5$ to $\mathrm{T} 9$, and from $3.8 \mathrm{~mm}$ to $8.6 \mathrm{~mm}$ for tests $\mathrm{T} 10$ to T12. 


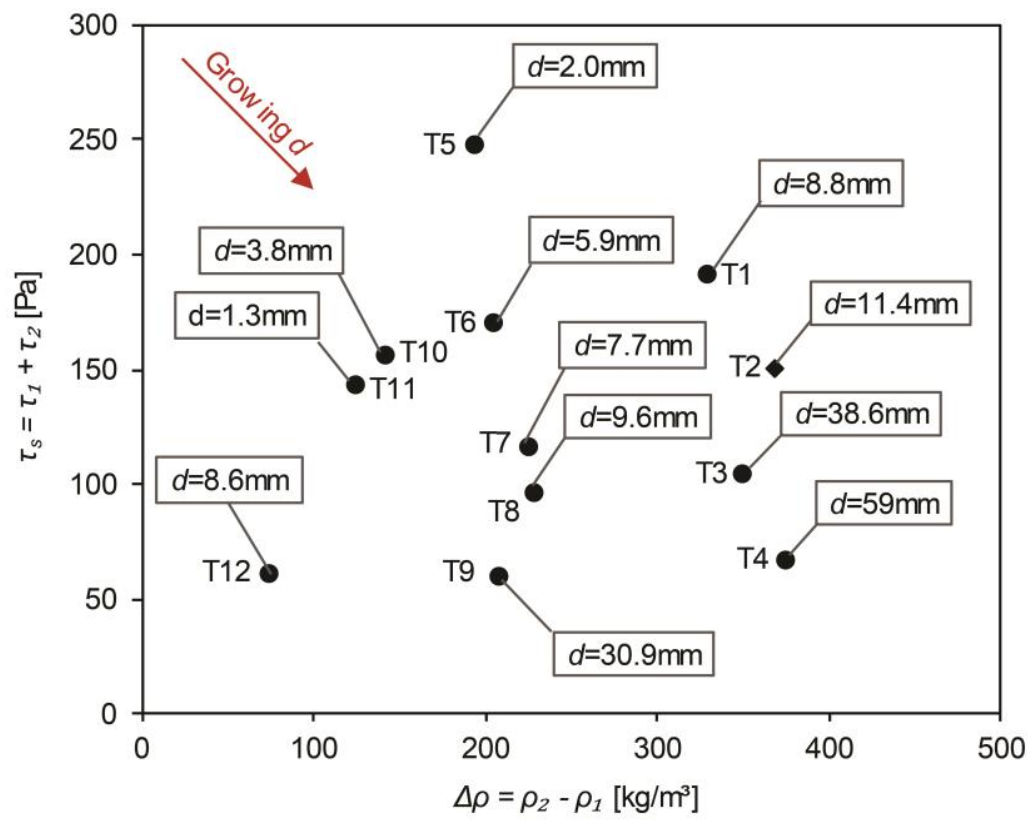

Figure 7 Relationship between sum of the yield stresses $\tau_{s}$, difference in densities of the materials $\Delta \rho$, and average horizontal displacement $d$ obtained for each test.

Figure 8 shows the maximum displacements $d_{A}$ and $d_{B}$ obtained for each test plotted against the corresponding stability coefficient $m$. The plot indicates that a relationship exists between the difference in density $\Delta \rho$ of the two materials, the sum of their yield stresses $\tau_{s}$, and the stability of the system. The displacements decrease with an increase in the stability coefficient $m$. Specifically $d$ decreases sharply for increasing stability coefficients $m$ up to about $0.4 \mathrm{~Pa} \mathrm{~m}^{3} \mathrm{~kg}^{-1}$ and then more gradually for higher values of $m$.

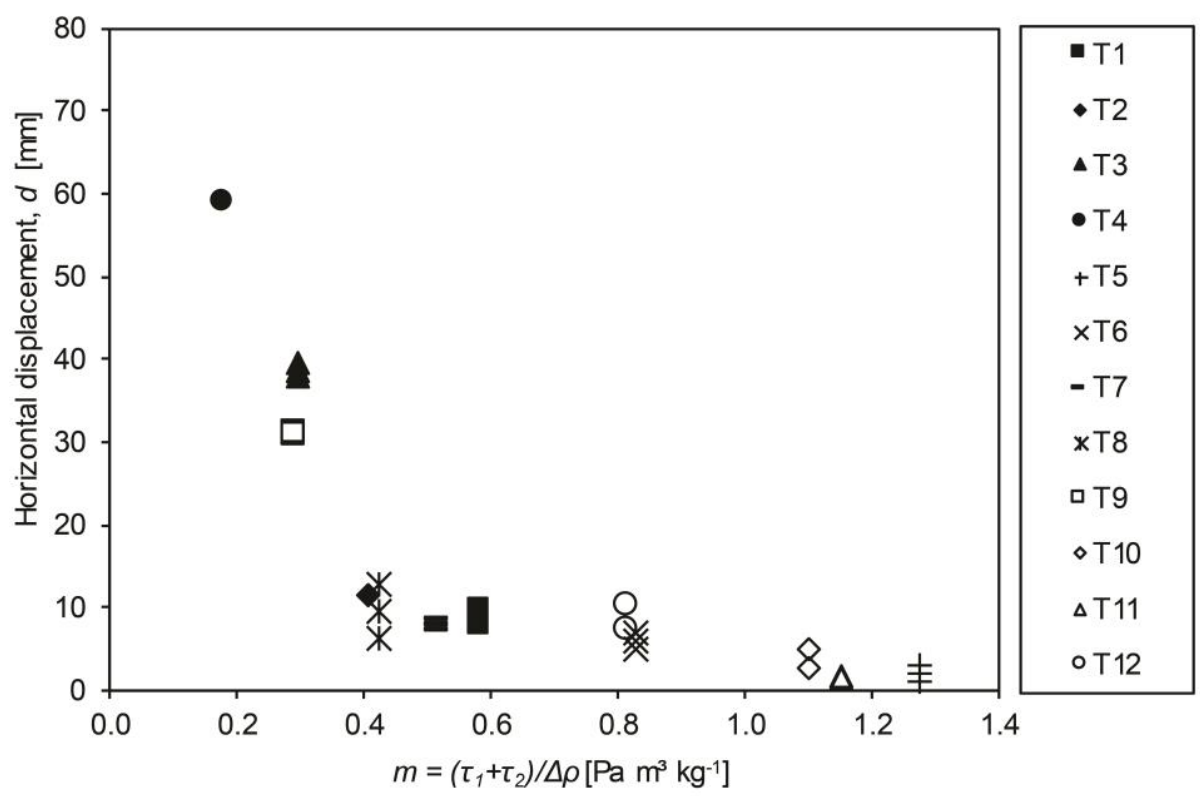

Figure 8 Maximum horizontal displacement $d$ as a function of the stability coefficient. 


\section{Limit state analysis}

This section presents a theoretical framework to assess the fresh state stability of a system composed of two columns of different cementitious materials. First, the adopted modelling strategy and underlying main assumptions are discussed. Two bound models are then presented that aim to bracket the real stability limit conditions. Finally, the newly formulated bound models are validated against the experimental results presented in section 2 .

\subsection{Cement-based materials as yield stress fluids}

Cement based materials, such as cement pastes, mortar and concrete, behave as yield stress fluids. A yield stress fluid is a material that exhibits a viscoelastic solid behaviour at low shear stresses but starts to flow at shear stresses higher than a threshold value, usually referred to as the yield stress. Most industrial materials characterised by the suspension of a large number of particles in a Newtonian fluid, such as water, behave as yield stress fluids [21,31,32]. Examples include creams, glues, paints, and muds [21,31]. Many yield stress fluids have a non-Newtonian character: their apparent viscosity varies with the shear rate due to the influence of the flow rate on the alignment and orientation of the suspended particles [28]. Such a behaviour is generally described by a Herschel-Bulkley model:

$$
\tau>\tau_{0} \rightarrow \tau=\tau_{0}+k \dot{\gamma}^{n}
$$

where $\tau_{0}$ is the yield stress, $\dot{\gamma}$ is the shear rate, $k$ is the consistency index, and $n$ is the flow index. The fluid is said to be shear thinning if $n$ is less than 1 , and shear thickening if $n$ is more than 1 . When $n$ is 1 , the model reduces to a Bingham behaviour and $k$ represents the viscosity $\eta$ of the fluid (see Figure 9):

$$
\tau>\tau_{0} \rightarrow \tau=\tau_{0}+\eta \dot{\gamma}
$$

When the apparent viscosity of the material not only depends on the shear rate but also on the flow history, the fluid is said to be complex or thixotropic [21]. In this case the effect of the flow rate on the alignment and orientation of the suspended particles takes some time to develop and the apparent rheological properties are time-dependent. This is illustrated by the fact that viscosity and yield stress grow with the time at rest and decrease with increasing flow time at a specific shear rate. Cementitious materials are rate-dependent and thixotropic yield stress fluids. Furthermore, time-dependent chemical reactions, such as cement hydration, lead to an irreversible evolution of the material properties. 


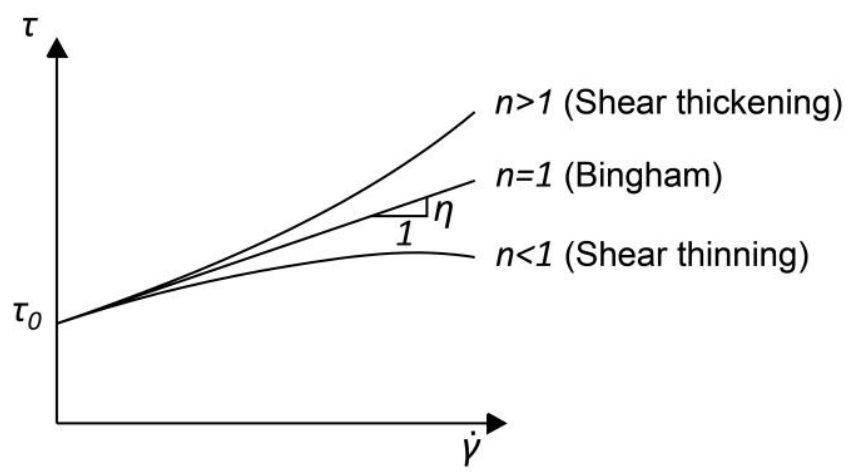

Figure 9 Herschel-Bulkley rheological model

The rheological properties of cement-based materials vary in a complex fashion with the mix proportions of their solid particles [23]. In cement paste, yield stress and viscosity increase as the water to cement ratio decreases [23]. In addition, both yield stress and viscosity increase as the cement gets finer. This is because the flow of cement paste is governed by the interfaces between solid cement particles and water [35]. If aggregate is progressively added to a cement paste to obtain a mortar or concrete, the workability of the mix is generally decreased [35]. In contrast to cement paste, in mortar and concrete both yield stress and viscosity increase as the maximum particle size increases [35]. The increase in yield stress can be explained by the fact that aggregate is capable of withstanding the applied stresses without deformation. The increase in viscosity can be partly attributed to the increase in inter-particle contact and surface interlocking. An additional contribution is associated with the inability of the aggregate to be sheared. When an overall shear rate $\dot{\gamma}$ is applied to an imaginary mortar or concrete, the shear rate within the aggregate particles is zero, while the shear rate in the paste can be significantly higher than $\dot{\gamma}$. This higher shear rate results in a higher shear stress in the paste. As a consequence, a higher viscosity is measured in the bulk materials. These trends suggest that the influence of particle size is a surface area effect in fine grained pastes and a simple volume effect in coarser grained concretes [35].

The workability of a given mix can also be adjusted by adding superplasticizers. These polymeric dispersants reduce yield stress at constant solids content [28]. Superplasticizer molecules adsorb onto cement particles and temporarily reduce or eliminate the attractive interparticle forces that cause yield stress. This gives the materials a more liquid consistency. The performance of superplasticizers is influenced by cement hydration. On reaction with water, hydrates form on the cement particles that tend to cluster and compensate for the superplasticizer's separating effect. This is because superplasticizer molecules interact with early hydration phases, mainly with the aluminate phases, by intercalation. This intercalation reduces the amount of polymer available for 
adsorption on the cement paste, thereby reducing the effectiveness of the plasticizer [36]. Hence, the yield stress measured in the bulk material is significantly influenced by the interaction between hydration products and superplasticizer molecules [28].

An additional parameter affecting the rheology of cementitious materials is temperature. Indeed, an increase in temperature can accelerate the physical and chemical phenomena underlying thixotropy and hydration. Furthermore, an increase in temperature can enhance the adsorption of some superplasticizers. Hence, temperature generally influences the time-dependent variation in yield stress and viscosity of the material $[28,37,38]$.

\subsection{Modelling strategy}

A number of computational techniques exist to perform concrete flow simulations $[29,30]$. Depending on the scale of the observation, fresh concrete can be studied as a homogeneous yield stress fluid or as a suspension of solid particles in a yield stress fluid [28,30]. Discrete modelling approaches are employed when, for example, the objective is to understand the relationship between mix design and rheological properties or when the scale of the problem is of the same order as the size of the grains [30]. Although generally more refined than continuous modelling methods, discrete modelling approaches still fail to capture a number of mechanisms that occur at a micro- and nano-scale, and influence the rheology of cementitious materials. These include chemical and physical interactions between cement grains, water and superplasticizer molecules. Furthermore, discrete modelling approaches require significant computational resources [30]. Thus, single fluid simulations are preferred when the behaviour of each particle is not of interest and relatively large problems are studied. A common approach to obtain single fluid solutions is to use the apparent viscosity of the material in Navier-Stokes equations. Nevertheless, the yield behaviour of cementitious materials makes the apparent viscosity approach infinite when the shear rate approaches zero. As a consequence, numerical difficulties arise when modelling the transition between solid and fluid behaviour; i.e. in the case of slow flows [30]. For this reason, the formulation of analytical methods to study the transition between solid and fluid regimes represents a major contribution to the field of applied concrete rheology.

\subsubsection{Cement-based materials as plastic materials}

In this work, the macroscopic behaviour of cementitious materials in the fresh state is studied through a novel analytical approach that models the material as perfectly plastic. In other words, it is assumed that either there is no flow or the flow is slow enough for viscous and inertia effects to be negligible [39]. This assumption 
allows the flow of the material to be studied as a function of the load conditions and yield stress of the material only [20,21]. Moreover, it provides a tool for the assessment of the limit-behaviour of systems whose boundary conditions are uncertain. It is worth noting that such an assumption is acceptable when the flow is slow enough such that the dynamic pressure $q$ (defined as the increase in pressure over the static value due to motion) is much smaller than the yield stress of the materials $\tau_{0}$ [39]. In the present study, the yield stress is formally treated as a time-independent measure, which means that the time-dependent changes in rheological properties can be set aside. This assumption is valid when the characteristic flow time for the studied problem is much smaller than the characteristic time over which the properties of the material change [31]. Such an approach allows the relationship between the instantaneous yield stress of the materials and the stability of the system to be determined. The obtained results can also be applied to problems where thixotropy and hydration play a major role by adopting a suitable model to describe the yield stress as a time-dependent material property [40].

In light of these assumptions, plasticity theory and its theorems of plastic collapse are employed to assess the stability of the studied system.

\subsubsection{Plasticity theory and theorems of plastic collapse}

The exact stability analysis of a perfectly plastic body would involve solving simultaneously equilibrium, compatibility and constitutive equations [41-43]. Specifically, the conditions that must be satisfied are as follows:

- Each point within the system must be in equilibrium.

- The strains occurring at any point must be compatible with the strains at all surrounding points.

- Stresses and strains at every point must be related through an appropriate constitutive relationship for the material.

- The failure criterion for the material should not be violated at any point in the system.

Thus, in order to achieve a complete analysis of the system, relatively complicated calculations would need to be performed. In general, this approach is impracticable for routine stability analyses [41-43].

An alternative to an exact analysis of the problem is to concentrate on the stability limit state and to ignore the elastic and partly-plastic preliminary stages. This approach is justified when the primary interest of the analysis is either to check that the system is stable or to ensure that plastic flow occurs. That is, when phenomena occurring prior to collapse, such as elastic deformation or vibration, are not of interest. This is the case for the problem studied here. 
A powerful technique for examining the stability limit state of plastic systems is the use of upper and lower bound methods of plasticity theory. Specifically, the upper bound method allows for an upper limit to the exact collapse load to be calculated by ignoring the equilibrium conditions; the lower bound method enables the calculation of a lower limit to the exact collapse load by ignoring the compatibility conditions. Rigorous proofs exist that the collapse loads obtained with upper and lower bound calculations bracket the true collapse load $[42,44]$.

\subsection{Bound models}

This section presents two original models for the stability assessment of a system composed of two vertical layers of plastic materials in a rigid container (see Figure 10). The two stability models, based on the upper and lower bound theorems of plasticity, aim to assess the relationships between material properties (density and yield stress), geometry, and stability of the system.

\subsubsection{Geometry and materials}

A system composed of two vertical columns of perfectly plastic materials resting next to each other is considered (see Figure 10). The two columns $I$ and $I I$ have a width $b$ and a height $h$ and are confined by a bottom surface and two lateral walls. The system is studied under the hypothesis of plane strain. In physical terms, this situation corresponds to the behaviour of an infinitely long container. The base and walls are assumed to be infinitely rigid and the effects of friction at the lateral walls and at the interface of materials are taken into account. Both lateral walls are assumed to be made of the same material and, thus, to have the same roughness. The two materials, denoted as 1 and 2, are assumed to have yield stresses $\tau_{1}$ and $\tau_{2}$ and mass densities $\rho_{1}$ and $\rho_{2}$ respectively. No additional external loads are applied to the two columns. Thus, the only external loads are represented by the self-weights of the materials. The two models are formulated assuming $\rho_{1} \geq \rho_{2}$. 


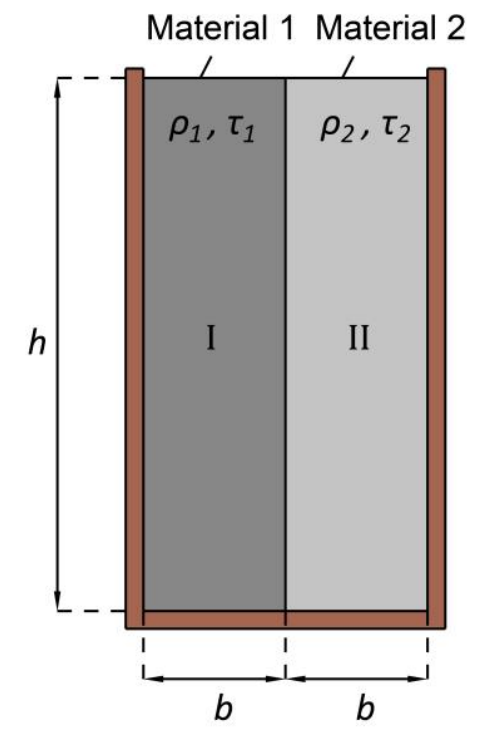

Figure 10 Geometry and materials

\subsubsection{Upper bound model}

To calculate an upper bound, it is necessary to define a compatible mechanism and to equate the work done by internal and external forces. The model developed here assumes the activation of the compatible mechanism shown in Figure 11a. Such a mechanism was defined where a heavier material flows underneath a lighter material. The kinematic model consists of two rectangular blocks $(A$ and $E)$, two triangular wedges $(B$ and $D)$ and two radial shear zones $\left(C_{1}\right.$ and $\left.C_{2}\right)$. Figure $11 \mathrm{~b}$ shows the corresponding displacement diagram. The radius of the radial shear zones $C_{1}$ and $C_{2}$ is $R=b / \sqrt{2}$ and their angle is $\theta_{f}=\pi / 4$. No-slip boundary conditions are assumed at the walls. 


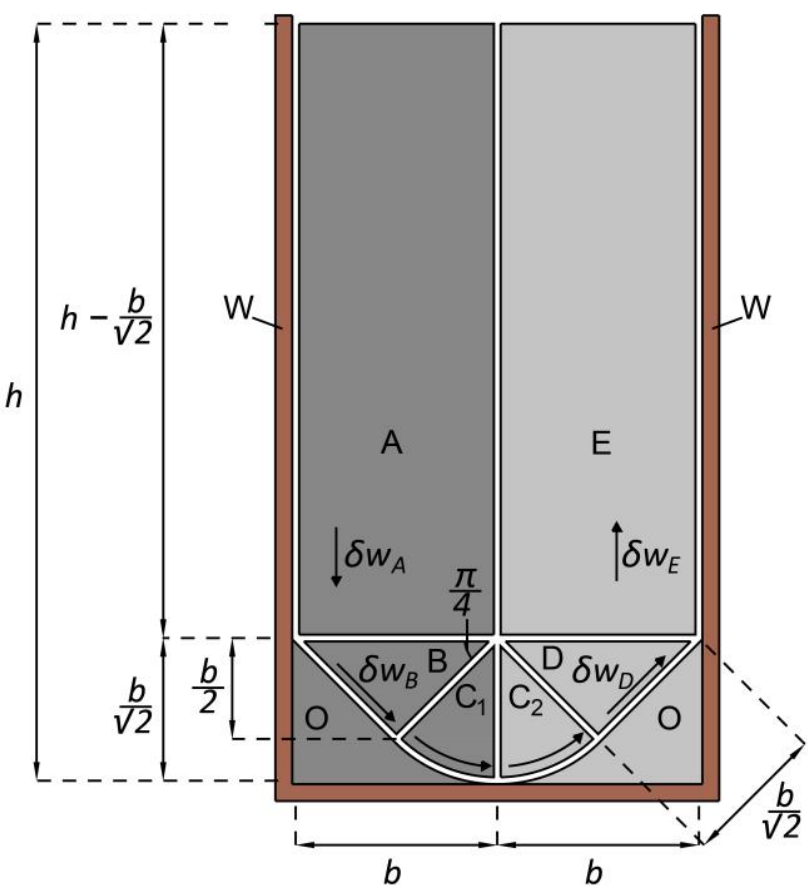

a)

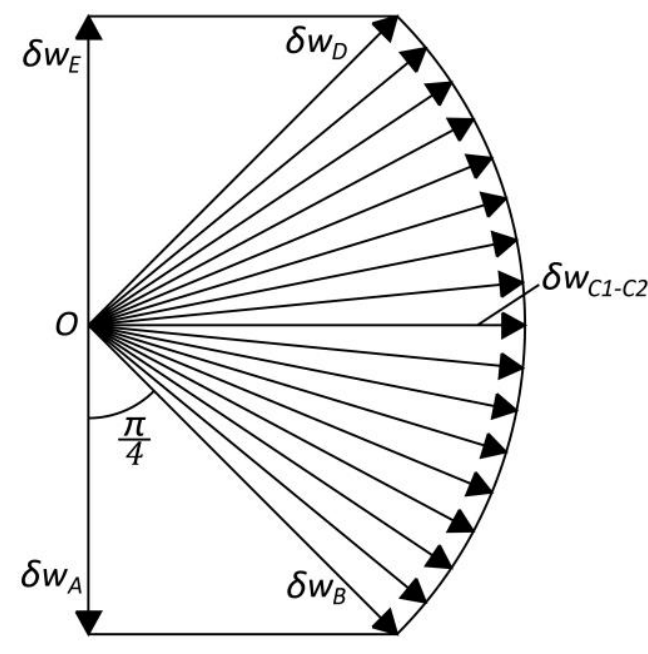

b)

Figure 11 Assumed mechanism (a) and corresponding displacement diagram (b)

Equating external and internal work for the considered mechanism, an upper bound of the external driving load $\Delta \rho g$ is obtained (see Appendix A) as:

$$
\Delta \rho g=\left(k_{U 1}+k_{U 2}+k_{U 3}\right)\left(\tau_{1}+\tau_{2}\right)
$$

where:

$$
\begin{array}{r}
k_{U 1}=\frac{\left(2+\frac{\pi}{2}\right) b}{b h-\frac{\sqrt{2}}{4} b^{2}} \\
k_{U 2}=\frac{\left(h-\frac{b}{\sqrt{2}}\right)}{b h-\frac{\sqrt{2}}{4} b^{2}} \\
k_{U 3}=\frac{\frac{2 \alpha}{\alpha+1}\left(h-\frac{b}{\sqrt{2}}\right)}{b h-\frac{\sqrt{2}}{4} b^{2}}
\end{array}
$$

and $\alpha$ is defined as the ratio between the minimum and the maximum of the two yield stresses. The terms $k_{U 1}$, $k_{U 2}$ and $k_{U 3}$ represent three different contributions to the stability of the system. Specifically, $k_{U 1}$ accounts 
for the energy needed to activate the internal slip surfaces and to deform the radial shear zones at the bottom of the system, $k_{U 2}$ captures for the effects of friction at the walls, and $k_{U 3}$ accounts for the impact of the stress at the interface between the two materials on the stability of the system.

The upper bound solution reported in Eq. (3-3) can be rearranged to express the sum $\tau_{s}$ of the yield stresses of the two materials that gives an unstable system for a given difference in density $\Delta \rho$ and system geometry:

$$
\tau_{s}=m_{U} \Delta \rho
$$

where:

$$
\begin{gathered}
\tau_{s}=\tau_{1}+\tau_{2} \\
m_{U}=\frac{g}{k_{U 1}+k_{U 2}+k_{U 3}}
\end{gathered}
$$

and $m_{U}$, defined here as the upper-bound stability coefficient, represents the maximum ratio between the sum $\tau_{s}$ of the yield stresses and difference in density $\Delta \rho$ that guarantees an unstable system. If the stability coefficient $m$ is lower than the upper-bound stability coefficient $m_{U}$, the system is expected to be unstable.

\subsubsection{Lower bound model}

To calculate a lower bound solution it is necessary to define an equilibrium stress state that does not violate the yield condition of the two materials. The assumed friction stresses are shown in Figure 12a. These represent two different interfaces:

i. The shear stress at the walls which equals the yield stress of the material, assuming perfect bond between material and walls.

ii. The shear stress along the boundary between the two materials which takes the minimum value $\tau_{\min }$ of the yield stresses $\tau_{1}$ and $\tau_{2}$. This interface stress contributes to the stability of the system by acting upwards on the heavier material and downwards on the lighter.

Since the critical stresses are expected to develop at the bottom of the system, the wall friction and material boundary interface stresses acting on the upper part of the system are modelled as equivalent distributed loads across the width of the columns [45]. Accordingly, an equilibrium stress state is defined here using equivalent uniform distributed vertical stresses $p_{1}$ and $p_{2}$ applied across the thickness of the two columns $I$ and $I I$ (see Figure 12b), where: 


$$
\begin{aligned}
& p_{1}=\frac{\tau_{1}+\tau_{\text {min }}}{b} \\
& p_{2}=\frac{\tau_{2}+\tau_{\text {min }}}{b}
\end{aligned}
$$

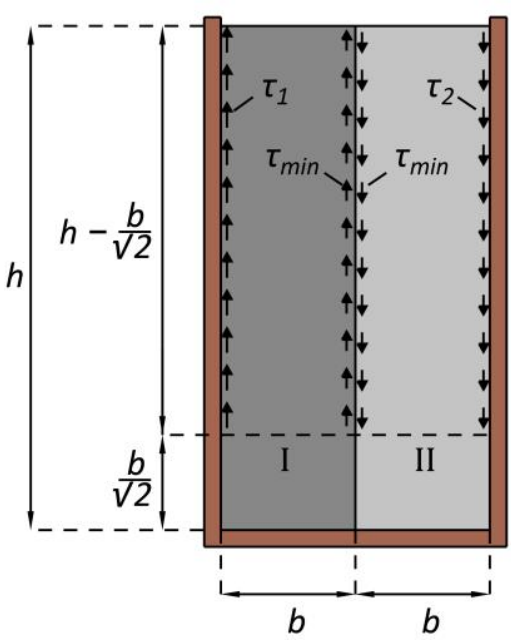

a)

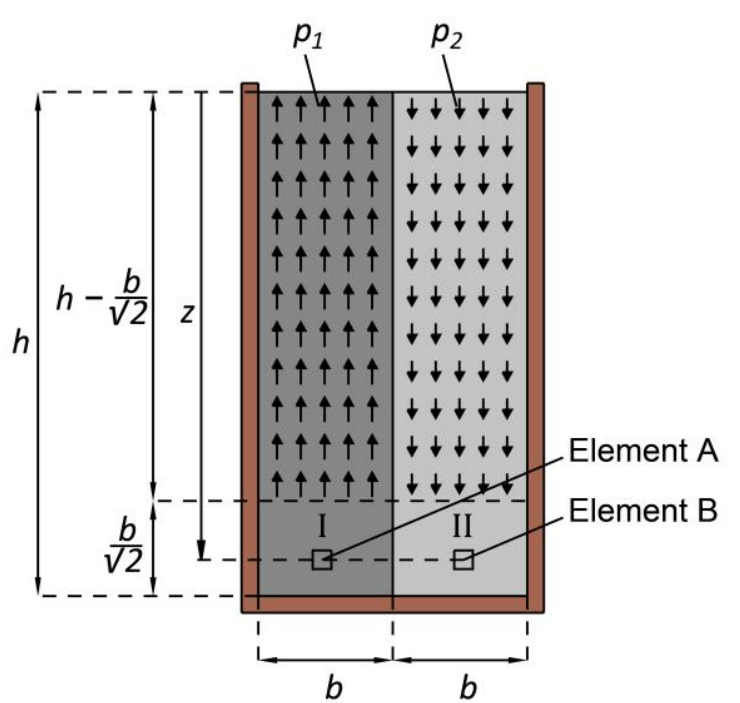

b)

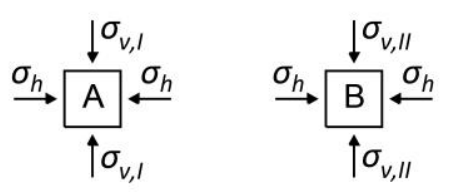

d)

Figure 12 (a) Assumed loading condition; (b) equivalent stress state with a vertical discontinuity; (c) stress states in the in a typical element $A ;(\mathrm{d})$ stress states in the in a typical element $B$

It is worth noting that in order for the distributed loads to be physically meaningful the following condition must be satisfied:

$$
p_{1} \leq \rho_{1} g
$$

That is, the friction force applied to the heavier material should not exceed the self-weight of the material itself.

Assuming that both materials reach their yield strength in shear at the base of the system, a lower bound of the external driving load $\Delta \rho g$ is obtained (see Appendix B) where: 


$$
\Delta \rho g=\left(k_{L 1}+k_{L 2}+k_{L 3}\right)\left(\tau_{1}+\tau_{2}\right)
$$

where:

$$
\begin{gathered}
k_{L 1}=\frac{2}{h} \\
k_{L 2}=\frac{\left(\frac{h}{b}-\frac{1}{\sqrt{2}}\right)}{h} \\
k_{L 3}=\frac{\frac{2 \alpha}{\alpha+1}\left(\frac{h}{b}-\frac{1}{\sqrt{2}}\right)}{h}
\end{gathered}
$$

The terms $k_{L 1}, k_{L 2}$ and $k_{L 3}$ capture the effects of the height of the system, friction at the walls and friction between the two materials respectively.

As for the upper bound model, the lower bound model solution reported in Eq. (3-13) can be rearranged to express the sum $\tau_{s}$ of the yield stresses of the two materials that gives a stable system for a given difference in density $\Delta \rho$ and system height $h$ :

$$
\tau_{s}=m_{L} \Delta \rho
$$

where:

$$
m_{L}=\frac{g}{k_{L 1}+k_{L 2}+k_{L 3}}
$$

$m_{L}$, defined as the lower-bound stability coefficient, represents the minimum ratio between the sum $\tau_{s}$ of the yield stresses and difference in density $\Delta \rho$ that guarantees stability. If a pair of mixes is selected that corresponds to a stability coefficient $m$ higher than the lower-bound stability coefficient $m_{L}$, the system is expected to be stable. 


\subsubsection{Validity domain and limit cases}

For both the upper and the lower bound model to be applicable, the ratio between system height and column width must satisfy the following condition:

$$
h \geq \frac{b}{\sqrt{2}}
$$

This condition is necessary for the lower part of the mechanism (blocks $\mathrm{B}, \mathrm{D}$ and radial shear zones $\mathrm{C}_{1}$ and $\mathrm{C}_{2}$ shown in Figure 11) to develop and for the assumption of equivalent distributed loads across the width of the columns (see Figure 12) to be acceptable.

The two models can be employed to evaluate the stability capacity of infinitely high parallel layers $(h \gg b)$.

In this case, the upper bound stability contributions $k_{U 1}, k_{U 2}$ and $k_{U 3}$ defined in Eq. (3-4), (3-5) and (3-6) respectively reduce to:

$$
\begin{gathered}
k_{U 1}=0 \\
k_{U 2}=\frac{1}{b} \\
k_{U 3}=\frac{2 \alpha}{\alpha+1} \frac{1}{b}
\end{gathered}
$$

Eq. (3-20) shows that, in this particular case, the energy needed to activate the internal slip surfaces and to deform the radial shear zones at the bottom of the system can be neglected. Eq. (3-21) and (3-22) show that the contributions to stability associated with both friction at the wall and the stresses at the interface between the vertical layers interface grow as the thickness $b$ of the layers decreases.

Similarly, the lower bound stability contributions $k_{L 1}, k_{L 2}$ and $k_{L 3}$ defined in Eq. (3-14), (3-15) and (3-16) respectively reduce to:

$$
\begin{gathered}
k_{L 1}=0 \\
k_{L 2}=\frac{1}{b} \\
k_{L 3}=\frac{2 \alpha}{\alpha+1} \frac{1}{b}
\end{gathered}
$$


As shown by Eq. (3-23), the contribution to stability associated with the system height disappears in this particular case. As for Eq. (3-21) and (3-22), Eq. (3-24) and (3-25) show that the contributions to stability associated with both friction at the wall and stresses at the layers interface grow as the thickness $b$ of the layers decreases.

\subsubsection{Stability, instability and plastic collapse}

The developed upper and lower bound models suggest that the stability capacity of the system grows with increasing $\operatorname{sum} \tau_{s}$ of the yield stresses and reduces with increasing difference in density $\Delta \rho$. That is, $\tau_{s}$ indicates the inner strength of the system and $\Delta \rho$ drives the external forces. The ratio between sum $\tau_{s}$ of the yield stresses and difference in density $\Delta \rho$ is here expressed in terms of stability coefficient $m$, see Eq. (2-1). For a given geometry and set of boundary conditions, the two bound models allow for the assessment of two limit values of the stability coefficient within which collapse is expected to occur.

Accordingly, three regions are defined in the plane $\tau_{s}-\Delta \rho$ (see Figure 13):

- A stability domain, defined by the lower bound model presented in Eq. (3-17).

- An instability domain, defined by the upper bound model presented in Eq. (3-7).

- A domain that lies in between the two bounds and within which the true plastic collapse occurs, according to the bound theorems of plasticity.

Thus, the models indicate that for a given geometry and set of boundary conditions, the stability of the system can be controlled by varying the yield stresses of the materials, $\tau_{1}$ and $\tau_{2}$, and the difference in density $\Delta \rho$. As discussed in section 3.1, in practical applications involving cementitious materials the yield stress of the materials can be lowered by chemical admixtures, such as superplasticizers, that have negligible effects on the wet densities. Hence, if an unstable system were to be desired, Eq. (3-7) can be used to define the minimum workability, and thus the required addition of admixtures, that leads to instability. Similarly, Eq. (3-17) can be used to determine the maximum workability, and thus the maximum amount of admixtures that ensures a stable system. 


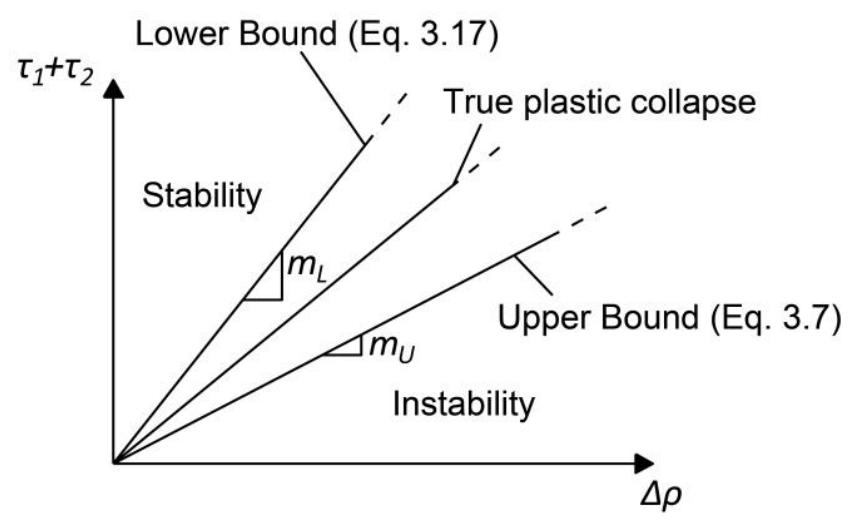

Figure 13 Lower and upper bound solutions

\subsection{Validation against experiments}

The formulated bound models were validated by evaluating the behaviour of the system studied experimentally (see section 2), having column width of $b=80 \mathrm{~mm}$ and a height of $h=300 \mathrm{~mm}$. In order to obtain indicative bounds for all tests, the following values of the coefficient $\alpha$ were selected:

- $\alpha=0.83$ for the upper bound. This value represents the maximum coefficient $\alpha$ for the mixes studied here (see Table 3).

- $\alpha=0.22$ for the lower bound. This value represents the minimum coefficient $\alpha$ for the mixes studied here (see Table 3).

Figure 14 reports the limit lines corresponding to the calculated lower and upper bound solutions using the models presented in section 3.3, together with the experimentally obtained relationship between sum of the yield stresses $\tau_{s}$, difference in densities of the materials $\Delta \rho$, and average horizontal displacement $d$ obtained for each test. Tests T1, T5, T6, T7, T10, T11 and T12 all fall within the stability domain identified by the lower bound model. Test T4 falls within the instability domains defined by the upper bound model. All the other tests lie between the stable and unstable regimes identified by the two bounds. 


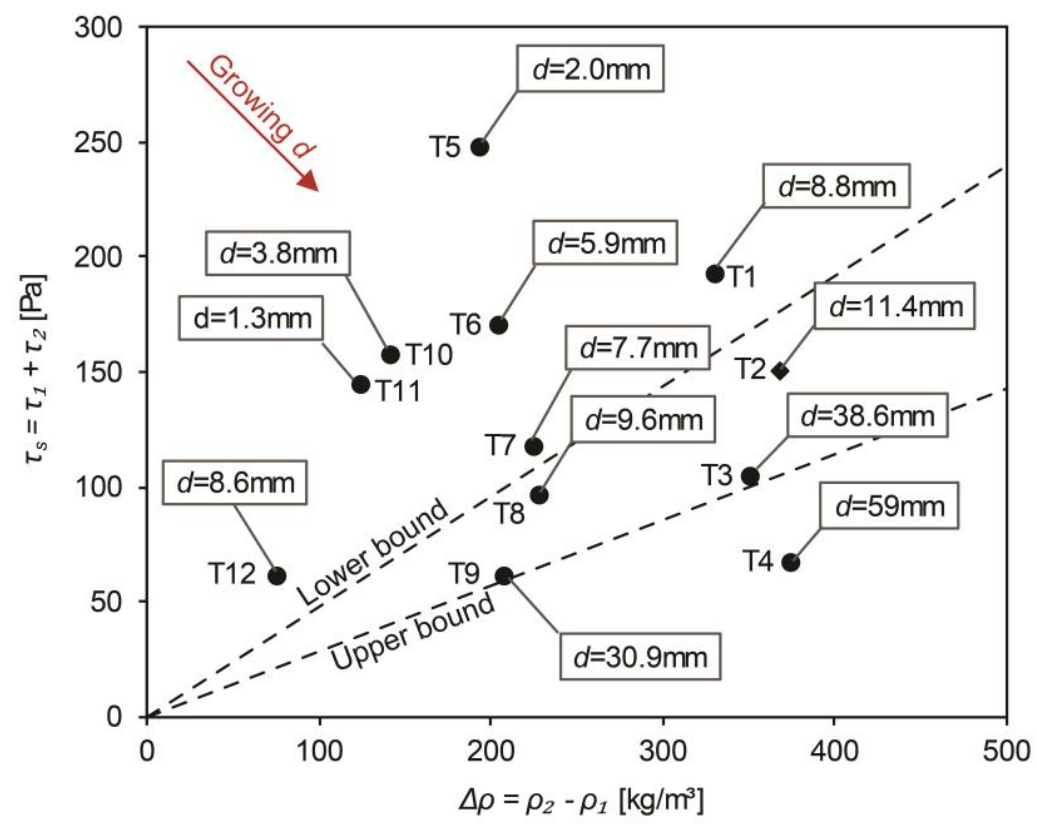

Figure 14 Analytical bound solutions and experimentally measured relationship between sum of the yield stresses $\tau_{s}$, difference in densities of the materials $\Delta \rho$, and average horizontal displacement $d$ obtained for each test.

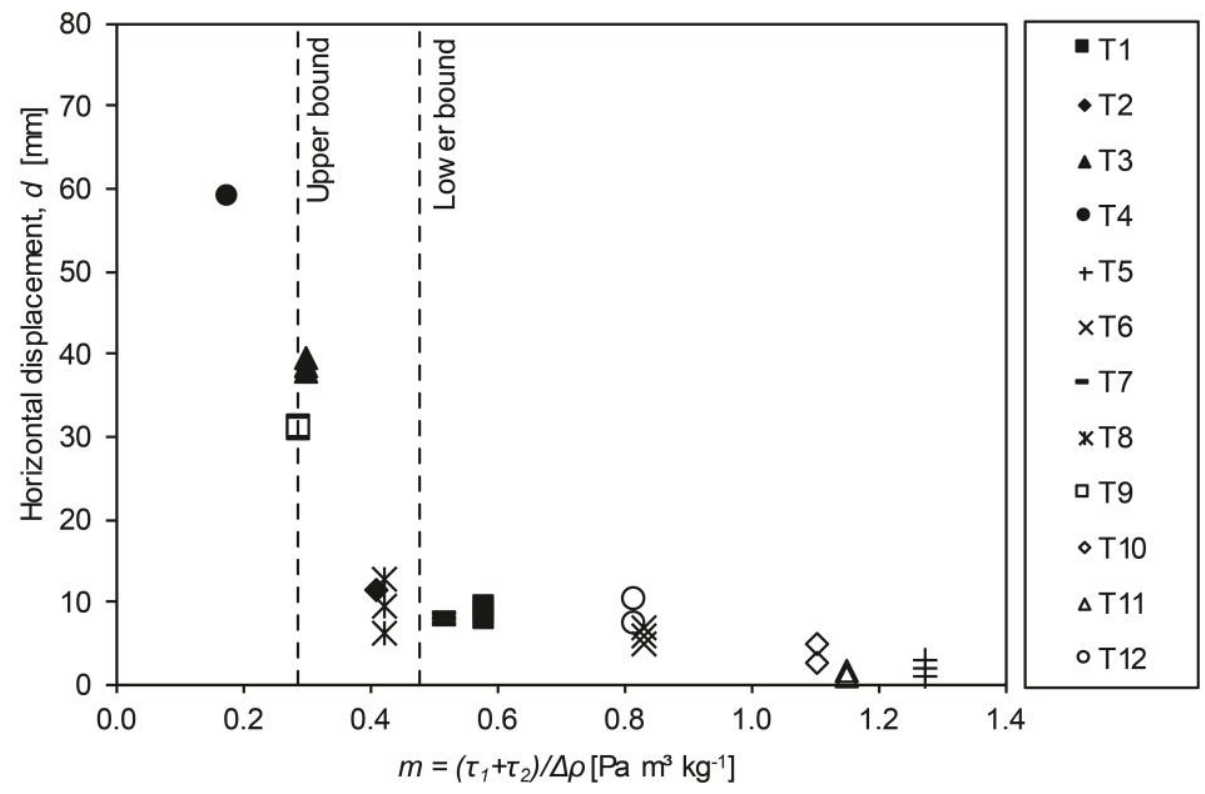

Figure 15 Analytical bound solutions and experimentally measured maximum horizontal displacement $d$ as a function of the stability coefficient.

Figure 15 shows limit lines corresponding to the calculated lower and upper bound solutions together with the maximum displacements $d_{A}$ and $d_{B}$ measured for each test plotted against the corresponding stability 
coefficient $m$. The plot indicates that the bound models bracket the sharp change in slope of the experimental $d-m$ curve occurring for a stability coefficient $m$ around $0.4 \mathrm{~Pa} \mathrm{~m}^{3} \mathrm{~kg}^{-1}$.

\section{Discussion}

The experimental results presented in section 2 suggest that, for a given system geometry and set of boundary conditions, the global stability of the system can be controlled by varying the sum $\tau_{s}$ of the yield stresses of the materials and their difference in density $\Delta \rho$. Specifically the stability capacity of the system may be increased either by increasing $\tau_{s}$ or by decreasing $\Delta \rho$. In this regard, Figure 14 shows that the maximum horizontal displacement $d$ of the boundary between the materials, taken as an indicator of the stability capacity of the system, decreases with increasing $\tau_{s}$ and decreasing $\Delta \rho$. This was confirmed with the formulated bound models, which suggest that the stability capacity of the system is proportional to the stability coefficient $m$, defined as the ratio between the sum of the yield stresses and the difference in density between the two materials (see Eq. (2-1), (3-7) and (3-17)).

The developed models aim to bracket the collapse of an ideal rigid-perfectly plastic material. However, real cementitious materials in the fresh state exhibit viscoelastic behaviour for stresses lower than the yield stress, i.e. they undergo instantaneous elastic strains and time-dependent creep deformations even for stress states that do not exceed the yield stress [21,23]. Furthermore, the presented models assume an initial state where two columns of different materials have a plane, vertical contact interface. Hence, they do not capture potential local instability flows due to the removal of the panel. It is also worth noting that the bound models treat the two mixes as homogeneous materials with uniform material properties. As a consequence, they are not able to capture local changes in properties due to potential bleeding and segregation. Nevertheless, in the experiments performed here, care was taken in the selection of the mixes to minimize bleeding and segregation.

The horizontal displacements measured in the hardened specimens are expected to represent the macroscopic effect of various factors including:

- Elastic strains.

- Local unstable flow due to the panel removal.

- Global unstable flow due to the difference in the weights of the two materials.

- Time-dependent creep strains that develop in the fresh cementitious mortars once global stability is reached. 
The complex material behaviour for stresses lower than the yield stresses, together with potential deflections of the panels during casting, explain the development of relatively small horizontal strains even in the case of high stability coefficients $m$. Indeed, for high stability coefficients $m$, stress states are expected to develop that do not exceed the yield strength in shear, and therefore would not trigger material liquid flow. Accordingly, the sharp increase in maximum horizontal displacement of the boundary observed for stability coefficients $m$ lower than $0.4 \mathrm{~Pa} \mathrm{~m}^{3} \mathrm{~kg}^{-1}$ suggests that flow due to global instability only develops in this region (Figure 15). The markedly nonlinear relationship between the stability coefficient $m$ and maximum horizontal displacement demonstrates that small changes in the yield stresses of the materials have a relatively high impact on the stability of the system for stability coefficients lower than $0.4 \mathrm{~Pa} \mathrm{~m}^{3} \mathrm{~kg}^{-1}$.

The calculated upper and lower bounds bracket experimentally identified regions between stable and unstable conditions, represented by stability coefficients of about $0.4 \mathrm{~Pa} \mathrm{~m}^{3} \mathrm{~kg}^{-1}$ (see Figure 15). This confirms that plasticity theory allows for the global instability flow of cementitious materials to be captured. Furthermore, the two bound solutions are relatively close to each other. This indicates that the postulated mechanism accurately describes the instability mode of the considered system and that the adopted simplified static scheme allows the effects of friction at the wall and at the materials boundary to be modelled approximately.

The proposed models can be adopted to design either stable or unstable systems. If the geometry and boundary conditions are fixed, the lower bound model can be employed to determine a set of material parameters $\tau_{1}, \tau_{2}$, $\rho_{1}$ and $\rho_{2}$ that ensures a stable system. Similarly, the upper bound model can be used to design an unstable system if instability is sought. If a pair of concrete mixes and thus a set of material properties are fixed, the lower and upper bound models can be employed to design geometries corresponding to stable or unstable systems respectively. The bound models proposed here for a system composed of two vertical layers of cementitious materials can be readily modified to study more complex geometries.

Visual inspection of the hardened specimens showed that the fresh materials stuck to the moulds. In addition, it was verified that the effects of friction along the walls did not influence the middle sections. This validates the choice of plain strain models to study the behaviour of such sections.

For the problem studied here, the duration of the flow was about 10 seconds, with maximum displacements of the order of $6 \mathrm{~cm}$. Thus, the maximum characteristic velocity was $V \sim 0.006 \mathrm{~ms}^{-1}$. With a typical density $\rho=$ $2400 \mathrm{~kg} \mathrm{~m}^{-3}$, a maximum characteristic dynamic pressure $q=\rho V^{2} / 2 \sim 0.04 \mathrm{~Pa}$ is obtained, a much smaller 
value than the yield stress of the materials studied $\left(\tau_{0}=11-176 \mathrm{~Pa}\right)$. This justifies the hypothesis of slow flows and, thus, validates the assumption of perfectly plastic material behaviour.

Furthermore, the relatively short duration of the flow confirms that the characteristic flow time is much smaller than the characteristic time over which the material properties change [31]. Hence, it is legitimate to treat the yield stress of the material as time-independent. In this regard, performing the rheological measurement immediately before the main test ensured a reliable assessment of the instantaneous yield stresses $\tau_{1}$ and $\tau_{2}$.

\section{Conclusions}

This study underpins research on functionally graded concrete by investigating for the first time the fundamental problem of the fresh state stability of vertical layers of cementitious materials. A system composed of two columns of cementitious materials that come into contact is specifically designed to probe the driving parameters for determination of intermixing. The relationship between system geometry, boundary conditions and material parameters is studied through original experiments and novel analytical models. The following conclusions can be drawn:

- For a given geometry and set of boundary conditions, a relationship exists between the sum of the yield stresses of the material, their difference in density and the global stability of the system. The maximum horizontal displacement of the materials' boundaries, considered as an indicator of instability was found to decrease with increasing stability coefficient, defined here as the ratio between the difference in density and sum of the yield stresses.

- Plasticity theory is used to study the solid-fluid limit state of concrete for the first time. An original plastic approach for predicting the stability of the system is presented. The approach allows an upper and a lower bound of the stability capacity of the system to be determined. Comparison with experimental data verified that the calculated upper and lower bounds bracket the actual stability limit state.

- The lower bound model allows for the determination of geometries, boundary conditions and material parameters that guarantee the stability of the system. Thus, if the geometry and boundary conditions are fixed and a stable system is to be designed, the model can be used to determine a set of material parameters $\tau_{1}, \tau_{2}, \rho_{1}$ and $\rho_{2}$ that ensure stability. Similarly, the upper bound model can be used to determine the minimum acceptable workability levels if instability is sought. If instead a set of material properties is given, the lower and upper bound models can be employed to determine the geometries and boundary conditions that guarantee stable and unstable systems respectively. 
- Plasticity theory can be successfully employed to study the behaviour of concrete in the transient solidfluid regime in the case of slow flows.

- The feasibility of manufacturing functionally graded elements composed of vertical layers of cementitious material is demonstrated.

\section{Acknowledgements}

The authors would like to acknowledge the financial support of EPSRC - the Engineering and Physical Sciences Research Council (UK) - through the Fellowship 'Tailored Reinforced Concrete Infrastructure: Boosting the Innate Response to Chemical and Mechanical Threats' [Project reference number: EP/N017668/1]. The authors also wish to extend their sincere thanks to Professor Christopher Calladine for the useful discussions. Finally, the authors would like to express their gratitude to Lorna Roberts and the staff of the University of Cambridge Structures Research Lab for their invaluable assistance in carrying out the experimental program previously reported. Additional data related to this publication is available at the University of Cambridge's institutional data repository: https://doi.org/10.17863/CAM.37979.

\section{Appendix A. Upper bound solution}

In order to obtain an upper bound of the external driving load $\Delta \rho g$ for the mechanism reported in Figure 11a, internal and external work are calculated and equated. The internal work is done by the shear stresses developing along the slip surfaces and within the radial shear zones. The shear stresses along the slip surfaces are defined as follows:

- The shear stress developing on slip surfaces between blocks of the same material (slip surfaces $O B$, $\left.A B, E D, O C_{1}, O C_{2}, O D\right)$ is the yield stress of the material itself.

- The shear stress on a slip plane between a block and a wall is the yield stress of the material of the block. That is, no-slip boundary conditions are assumed at the walls [25]. Hence, the stresses $\tau_{w 1}$ and $\tau_{w 2}$ developing along WA and WE respectively are defined as:

$$
\begin{gathered}
\tau_{w 1}=\tau_{1} \\
\tau_{w 2}=\tau_{2}
\end{gathered}
$$


- The shear stress along slip plane $A E$, located at the boundary between the two blocks of materials 1 and 2 , is the minimum value $\tau_{\min }$ of the yield stresses $\tau_{1}$ and $\tau_{2}$. That is, it is assumed that plastic flow develops in the material with a lower yield stress. The minimum yield stress value $\tau_{\min }$ is expressed as a function of the sum of the yield stresses $\tau_{1}$ and $\tau_{2}$ :

$$
\tau_{\min }=\left(\tau_{1}+\tau_{2}\right) \frac{\alpha}{\alpha+1}
$$

where $\alpha$ is defined as the ratio between the two yield stresses:

$$
\alpha=\frac{\tau_{\min }}{\tau_{\max }}
$$

and $\tau_{\max }$ is the maximum of the two yield stresses. Thus, $\alpha$ assumes values between 0 and 1 .

The shear zones represent slip fans composed of an infinite number of rigid triangular blocks. The internal work contribution due to the deformation of a slip fan composed a finite number of triangles can be obtained by summing the work due to the tangential slip surfaces and the radial slip surfaces $[42,46]$. When the number of triangles subdividing the fan approaches infinity, the internal work contribution $\delta W_{i n t, r}$ due to the deformation of a generic radial shear zone is calculated as [42,46]:

$$
\delta W_{\text {int }, r}=\tau_{0} R \theta_{f} \delta w
$$

where $\tau_{0}$ is the yield stress of the material, $R$ is the radius of the fan, $\theta_{f}$ is the fan angle which is equal to the change $\theta$ in the direction of the vector of displacement $\delta w$ across the radial shear zone.

Thus, the internal work contributions $\delta W_{i n t, C 1}$ and $\delta W_{i n t, C 2}$ associated with the deformation of the radial shear zones $C_{1}$ and $C_{2}$ are:

$$
\begin{aligned}
& \delta W_{\text {int }, C 1}=\tau_{1} \frac{b}{\sqrt{2}} \frac{\pi}{4}\left(\sqrt{2} \delta w_{A}\right)=\frac{\pi}{4} \tau_{1} b \delta w_{A} \\
& \delta W_{\text {int }, C 2}=\tau_{2} \frac{b}{\sqrt{2}} \frac{\pi}{4}\left(\sqrt{2} \delta w_{A}\right)=\frac{\pi}{4} \tau_{2} b \delta w_{A}
\end{aligned}
$$

Accordingly, the sum of the internal work contributions gives:

$$
\delta W_{\text {int }}=\sum_{i} \delta W_{\text {int }, i}=\delta w_{A}\left(\tau_{1}+\tau_{2}\right)\left[\left(h-\frac{b}{\sqrt{2}}\right)+\left(2+\frac{\pi}{2}\right) b+\frac{2 \alpha}{\alpha+1}\left(h-\frac{b}{\sqrt{2}}\right)\right]
$$


For the considered mechanism, the increment of external work $\delta W_{\text {ext }}$ is due to the self-weight forces and is given by:

$$
\delta W_{\text {ext }}=\sum_{i} \delta W_{e x t, i}=\delta w_{A} g\left(\rho_{1}-\rho_{2}\right)\left(b h-\frac{\sqrt{2}}{4} b^{2}\right)
$$

where $\delta W_{\text {ext,i }}$ is the increment of work done by the self-weight force of the $i$-th block and $\delta w_{A}$ is the displacement of block $A$. It is worth noting that for the radial shear zones $C_{1}$ and $C_{2}$ the average vertical displacement was considered.

Equating external and internal work, given by Eq. (A-9) and Eq. (A-8) respectively, an upper bound of the external driving load $\Delta \rho g$ is obtained where:

$$
\Delta \rho g=\frac{\left(2+\frac{\pi}{2}\right) b+\left(h-\frac{b}{\sqrt{2}}\right)+\frac{2 \alpha}{\alpha+1}\left(h-\frac{b}{\sqrt{2}}\right)}{b h-\frac{\sqrt{2}}{4} b^{2}}\left(\tau_{1}+\tau_{2}\right)
$$

Eq. (A-10) can be written as:

$$
\Delta \rho g=\left(k_{U 1}+k_{U 2}+k_{U 3}\right)\left(\tau_{1}+\tau_{2}\right)
$$

where:

$$
\begin{array}{r}
k_{U 1}=\frac{\left(2+\frac{\pi}{2}\right) b}{b h-\frac{\sqrt{2}}{4} b^{2}} \\
k_{U 2}=\frac{\left(h-\frac{b}{\sqrt{2}}\right)}{b h-\frac{\sqrt{2}}{4} b^{2}} \\
k_{U 3}=\frac{\frac{2 \alpha}{\alpha+1}\left(h-\frac{b}{\sqrt{2}}\right)}{b h-\frac{\sqrt{2}}{4} b^{2}}
\end{array}
$$




\section{Appendix B. Lower bound solution}

In order to obtain an upper bound of the external driving load $\Delta \rho g$ for the equilibrium stress state schematized in Figure 12, it is assumed that both materials reach their yield strength in shear at the base of the system. The considered stress state defined for the lower bound model presents a vertical stress discontinuity at the interface of the two materials (see Figure 12b, Figure 12c, Figure 12d). Vertical and horizontal directions are the directions of the principal stresses. The vertical stresses $\sigma_{v, I}$ and $\sigma_{v, I I}$ in a typical element $A$ and $B$ in regions $I$ and $I I$, for $z \geq h-b / \sqrt{2}$, are given by:

$$
\begin{gathered}
\sigma_{v, I}=\rho_{1} g z-p_{1}\left(h-\frac{b}{\sqrt{2}}\right)=\rho_{1} g z-\left(\tau_{1}+\tau_{\min }\right)\left(\frac{h}{b}-\frac{1}{\sqrt{2}}\right) \\
\sigma_{v, I I}=\rho_{2} g z+p_{2}\left(h-\frac{b}{\sqrt{2}}\right)=\rho_{2} g z+\left(\tau_{2}+\tau_{\min }\right)\left(\frac{h}{b}-\frac{1}{\sqrt{2}}\right)
\end{gathered}
$$

where $z$ is the depth of the element and $g$ is the gravitational acceleration. In order to meet the equilibrium condition at the stress discontinuity, the horizontal normal stress $\sigma_{h}$ should be continuous across the stress boundary [41]. Thus, the two Mohr's circles describing the stress states at the bottom of the two regions must share a tangent. In order to calculate a lower bound on the loads, it is assumed that both materials reach their yield strength in shear at the base of the system. As a consequence, the stress states in the two elements A and B located at $z=h$ can be represented by two Mohr's circles having radii $\tau_{1}$ and $\tau_{2}$ respectively, as shown in Figure B.1.

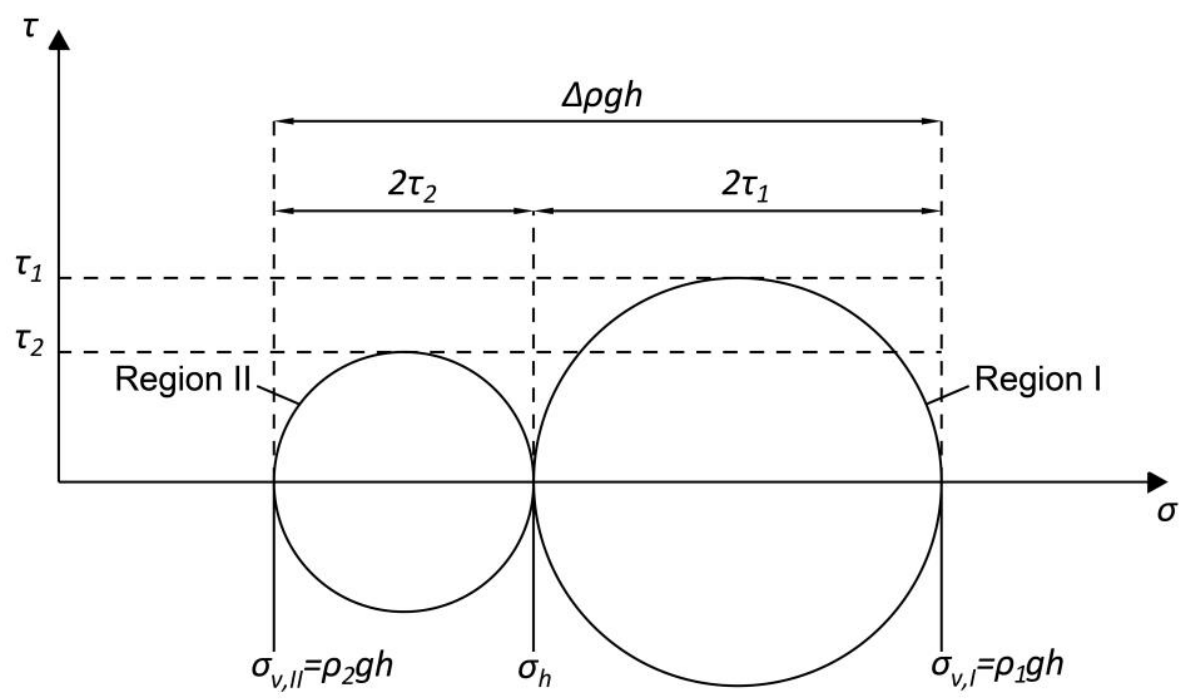

Figure B.1 Equilibrium stress field at the base of the system $(z=h)$

From the geometry of Figure B.1, the maximum difference in vertical stresses at $z=h$ can be written as: 


$$
\sigma_{v, I}(z=h)-\sigma_{v, I I}(z=h)=2\left(\tau_{1}+\tau_{2}\right)
$$

where $\sigma_{v, I}(z=h)$ and $\sigma_{v, I I}(z=h)$ are the vertical stresses at the bottom of region $I$ and $I I$ respectively. It is worth noting that, although in Figure B.1 it is assumed $\tau_{1}>\tau_{2}$, Eq. (B-3) is valid also in the case where $\tau_{1} \leq$ $\tau_{2}$.

Combining Eq. (B-1), (B-2), (B-3) and (A-3), a lower bound of the external driving load $\Delta \rho g$ is obtained where:

$$
\Delta \rho g=\left(\tau_{1}+\tau_{2}\right) \frac{2+\left(\frac{h}{b}-\frac{1}{\sqrt{2}}\right)+\frac{2 \alpha}{\alpha+1}\left(\frac{h}{b}-\frac{1}{\sqrt{2}}\right)}{h}
$$

Eq. (B-4) can be written as:

$$
\Delta \rho g=\left(k_{L 1}+k_{L 2}+k_{L 3}\right)\left(\tau_{1}+\tau_{2}\right)
$$

where:

$$
\begin{gathered}
k_{L 1}=\frac{2}{h} \\
k_{L 2}=\frac{\left(\frac{h}{b}-\frac{1}{\sqrt{2}}\right)}{h} \\
k_{L 3}=\frac{\frac{2 \alpha}{\alpha+1}\left(\frac{h}{b}-\frac{1}{\sqrt{2}}\right)}{h}
\end{gathered}
$$

\section{References}

[1] U.S. Geological Survey. Mineral Commodity Summaries: Cement. Available at: http://minerals.usgs.gov/minerals/pubs/ commodity/cement/. U.S. Geological Survey; 2016.

[2] Boden T, Andres R, Marland G. Global, Regional, and National Fossil-Fuel CO2 Emissions. Oak Ridge, Tenn., U.S.A.: Carbon Dioxide Information Analysis Center, Oak Ridge National Laboratory, U.S. Department of Energy; 2013. doi:10.3334/CDIAC/00001_V2013. 
[3] United Nations. Emission Gap Report 2018. 2018.

[4] United Nations. Adoption of the Paris Agreement. Report No. FCCC/CP/2015/L.9/Rev.1. 2015.

[5] Xiaohong T, Yue QZQ. Fracture Mechanics in Layered and Graded Solids, Analysis Using Boundary Element Methods. Berlin, Boston: De Gruyter; 2014. doi:10.1515/9783110297973.

[6] Koizumi M. FGM activities in Japan. Compos Part B Eng 1997;28:1-4. doi:10.1016/S13598368(96)00016-9.

[7] Naebe M, Shirvanimoghaddam K. Functionally graded materials: a review of fabrication and properties. Appl Mater Today 2016;5:223-45. doi:10.1016/J.APMT.2016.10.001.

[8] Kieback B, Neubrand A, Riedel H. Processing techniques for functionally graded materials. Mater Sci Eng A 2003;362:81-106. doi:10.1016/S0921-5093(03)00578-1.

[9] Mahamood RM, Akinlabi ET. Functionally Graded Materials. Springer; 2017. doi:10.1007/978-3-31953756-6.

[10] Jha DK, Kant T, Singh RK. A critical review of recent research on functionally graded plates. Compos Struct 2013;96:833-49. doi:10.1016/J.COMPSTRUCT.2012.09.001.

[11] Markworth AJ, Ramesh KS, Parks WP. Modelling studies applied to functionally graded materials. J Mater Sci 1995;30:2183-93. doi:10.1007/BF01184560.

[12] Suresh S, Mortensen A. Functionally graded metals and metal-ceramic composites: Part 2 Thermomechanical behaviour. Int Mater Rev 1997;42:85-116. doi:10.1179/imr.1997.42.3.85.

[13] Mortensen A, Suresh S. Functionally graded metals and metal-ceramic composites: Part 1 Processing. Int Mater Rev 1995;40:239-65. doi:10.1179/imr.1995.40.6.239.

[14] Udupa G, Rao SS, Gangadharan KV. Functionally Graded Composite Materials: An Overview. Procedia Mater Sci 2014;5:1291-9. doi:10.1016/J.MSPRO.2014.07.442.

[15] Toader N, Sobek W, Nickel KG. Energy absorption in functionally graded concrete bioinspired by sea urchin spines. J Bionic Eng 2017;14:369-78. doi:10.1016/S1672-6529(16)60405-5.

[16] Herrmann M, Sobek W. Functionally graded concrete: Numerical design methods and experimental tests of mass-optimized structural components. Struct Concr 2016;18:54-66. doi:10.1002/suco.201600011.

[17] Roesler J, Paulino G, Gaedicke C, Bordelon A, Park K. Fracture behavior of functionally graded concrete materials for rigid pavements. Transp Res Rec J Transp Res Board 2007;2037:40-9.

[18] Evangelista F, Roesler J, Paulino G. Numerical simulations of fracture resistance of functionally graded concrete materials. J Transp Res Board 2009:122-31.

[19] Zhang J, Li VC. Monotonic and fatigue performance in bending of fiber-reinforced engineered cementitious composite in overlay system. Cem Concr Res 2002;32:415-23. doi:10.1016/S00088846(01)00695-0.

[20] Heinz P, Herrmann M, Sobek W. Production method and application of functionally graded components in construction (Herstellungsverfahren und Anwendungsbereiche für funktional gradierte Bauteile im Bauwesen). Stuttgart: Fraunhofer IRB Verlag; 2012.

[21] Coussot P. Yield stress fluid flows: A review of experimental data. J Nonewtonian Fluid Mech 2014;211:31-49. doi:10.1016/j.jnnfm.2014.05.006.

[22] Tattersall GH, Banfill PFG. The Rheology of Fresh Concrete. Boston: Pitman Books Limited; 1983.

[23] Banfill PFG. Rheology of fresh cement and concrete. Rheol. Rev. 2006, The British Society of 
Rheology; 2006, p. 61-130.

[24] European Committe for Standardization. EN 197-1:2011 - Cement - Part 1: Composition, specifications and conformity criteria for common cements 2011.

[25] Roussel N. The LCPC BOX: a cheap and simple technique for yield stress measurements of SCC. Mater Struct 2007;40:889-96. doi:10.1617/s11527-007-9230-4.

[26] Roussel N. Correlation between yield stress and slump: comparison between numerical simulations and concrete rheometers results. Mater Struct 2006;39:501. doi:10.1617/s11527-005-9035-2.

[27] Nguyen TLH, Roussel N, Coussot P. Correlation between L-box test and rheological parameters of a homogeneous yield stress fluid. Cem Concr Res 2006;36:1789-96. doi:10.1016/J.CEMCONRES.2006.05.001.

[28] Roussel N. Understanding the Rheology of Concrete. Woodhead Publishing; 2012.

[29] Roussel N, Gram A, Cremonesi M, Ferrara L, Krenzer K, Mechtcherine V, et al. Numerical simulations of concrete flow: A benchmark comparison. Cem Concr Res 2016;79:265-71. doi:10.1016/J.CEMCONRES.2015.09.022.

[30] Roussel N, Geiker MR, Dufour F, Thrane LN, Szabo P. Computational modeling of concrete flow: General overview. Cem Concr Res 2007;37:1298-307. doi:https://doi.org/10.1016/j.cemconres.2007.06.007.

[31] Coussot P. Saffman-Taylor instability in yield-stress fluids. J Fluid Mech 1999;380:S002211209800370X. doi:10.1017/S002211209800370X.

[32] Bird RB, Dai GC, Yarusso BJ. The rheology and flow of viscoplastic materials. Rev Chem Eng 1983;1:1. doi:10.1515/revce-1983-0102.

[33] Tattersall GH. Workability and Quality Control of Concrete. CRC Press; 2014.

[34] Wallevik OH. The Rheology of Fresh Concrete and its Application on Concrete with and without Silica Fume. 1990.

[35] Banfill PFG. The rheology of fresh cement and concrete - a review. Proc 11th Int. Cem. Chem. Congr., Durban: 2003.

[36] Flatt RJ. Polymeric Dispersants in Concrete, Polymers in Particulate Systems: Properties and Applications. Marcel Dekker, New York; 2001.

[37] Petit J-Y, Khayat KH, Wirquin E. Coupled effect of time and temperature on variations of yield value of highly flowable mortar. Cem Concr Res 2006;36:832-41. doi:10.1016/J.CEMCONRES.2005.11.001.

[38] Petit J-Y, Khayat KH, Wirquin E. Coupled effect of time and temperature on variations of plastic viscosity of highly flowable mortar. Cem Concr Res 2009;39:165-70. doi:10.1016/J.CEMCONRES.2008.12.007.

[39] Roussel N, Coussot P. "Fifty-cent rheometer" for yield stress measurements: from slump to spreading flow. J Rheol 2005;49:705-18. doi:10.1122/1.1879041.

[40] Roussel N, Cussigh F. Distinct-layer casting of SCC: The mechanical consequences of thixotropy. Cem Concr Res 2008;38:624-32. doi:10.1016/J.CEMCONRES.2007.09.023.

[41] Calladine CR. Plasticity for engineers. Woodhead Publishing; 2010. doi:https://doi.org/10.1533/9780857099709.93.

[42] Chen WF. Limit analysis and soil plasticity. Elsevier Science; 2013. 
[43] Chen W. Plasticity, limit analysis and structural design. Int J Solids Struct 2000;37:81-92. doi:10.1016/S0020-7683(99)00079-7.

[44] Heyman J. Basic structural theory. Cambridge: Cambridge University Press; 2008. doi:10.1017/CBO9780511754487.

[45] de Saint-Venant B. Memoire sur la torsion des prismes: avec des considérations sur leur fléxion ainsi que sur l'équilibre intérieur des solides élastiques en général, et des formules pratiques pour le calcul de leur résistance à divers efforts s'exerçant simultanément. S.l.; 1853.

[46] Atkinson J. The Mechanics of Soils and Foundations. CRC Press; 2007. 